NBER WORKING PAPER SERIES

\title{
HOW IMPORTANT ARE INVESTMENT INDIVISIBILITIES FOR DEVELOPMENT? EXPERIMENTAL EVIDENCE FROM UGANDA
}

\author{
Joseph P. Kaboski \\ Molly Lipscomb \\ Virgiliu Midrigan \\ Carolyn Pelnik \\ Working Paper 29773 \\ http://www.nber.org/papers/w29773 \\ NATIONAL BUREAU OF ECONOMIC RESEARCH \\ 1050 Massachusetts Avenue \\ Cambridge, MA 02138 \\ February 2022
}

We thank Erin Byrne, Shoshana Griffith, Regina Mannino, Grant Nelson, and Elizabeth Vranas for excellent research assistance. We thank participants for comments received on presentations of earlier versions of this research at Harvard/MIT, Ohio State, PUC Chile, and Y-RISE. Special thanks to Cynthia Kinnan for her insightful discussion of the paper at Y-RISE. We are grateful to the Kellogg Institute, the National Institute of Health, MasterCard Foundation, the Gates Foundation, and STEG for funding this project and research. This project was reviewed and approved by the Institutional Review Boards of the University of Notre Dame and the Uganda National Council for Science and Technology. This RCT was registered in the American Economic Association Registry for randomized control trials under trial number, AEARCTR-0002217. The views expressed herein are those of the authors and do not necessarily reflect the views of the National Bureau of Economic Research.

At least one co-author has disclosed additional relationships of potential relevance for this research. Further information is available online at http://www.nber.org/papers/w29773.ack

NBER working papers are circulated for discussion and comment purposes. They have not been peer-reviewed or been subject to the review by the NBER Board of Directors that accompanies official NBER publications.

(C) 2022 by Joseph P. Kaboski, Molly Lipscomb, Virgiliu Midrigan, and Carolyn Pelnik. All rights reserved. Short sections of text, not to exceed two paragraphs, may be quoted without explicit permission provided that full credit, including $\odot$ notice, is given to the source. 
How Important are Investment Indivisibilities for Development? Experimental Evidence from Uganda

Joseph P. Kaboski, Molly Lipscomb, Virgiliu Midrigan, and Carolyn Pelnik

NBER Working Paper No. 29773

February 2022

JEL No. O11,O12,O16

\section{ABSTRACT}

Theoretically, indivisible investments together with financial frictions can lower development, generate poverty traps, and lead agents to become risk-loving. Using experimental cash grants involving a choice between a safer, low payoff and a riskier, large payoff lottery, we find that 27 percent choose the riskier, larger lottery. Small grant winners invest in livestock and business inventory, while large grant winners invest in land, which exhibits high capital gains. Our quantitative model shows that the aggregate effects of financial deepening are sizable if the indivisible investment can be accumulated (e.g., capital) but not if it is in fixed supply (e.g., land).

$\begin{array}{ll}\text { Joseph P. Kaboski } & \text { Virgiliu Midrigan } \\ \text { Department of Economics } & \text { Department of Economics } \\ \text { University of Notre Dame } & \text { New York University } \\ \text { 3039 Nanovic Hall } & \text { 19 W. 4th St. } \\ \text { Notre Dame, IN 46556 } & \text { New York, NY } 10012 \\ \text { and NBER } & \text { and NBER } \\ \text { jkaboski@nd.edu } & \text { virgiliu.midrigan@ nyu.edu } \\ & \\ \text { Molly Lipscomb } & \text { Carolyn Pelnik } \\ \text { University of Virginia } & \text { Tufts University } \\ \text { 235 McCormick Ave } & \text { Department of Economics } \\ \text { Charlottesville, VA 22904 } & \text { 177 College Ave } \\ \text { molly.lipscomb@ virginia.edu } & \text { Medford, MA 02155 } \\ & \text { USA } \\ & \text { carolyn.pelnik@ tufts.edu }\end{array}$

A data appendix is available at http://www.nber.org/data-appendix/w29773 


\section{Introduction}

Theory suggests that high yield, indivisible investment opportunities can play crucial roles in development. In particular, at the micro level, they can help explain entrepreneurship decisions and savings dynamics (Buera, 2009; Midrigan and Xu, 2014), can lead to poverty traps (Banerjee and Newman, 1993; Buera et al., 2014), and are important in predicting the effects of financial interventions and poverty programs (Kaboski and Townsend, 2011; Buera et al., 2015; Banerjee et al., 2019; Buera et al., 2020). At the aggregate level, they are also critical in understanding the quantitative importance of financial frictions on output, productivity, and investment (Buera et al., 2014; Midrigan and Xu, 2014).

Indivisibilities in high yield investments imply that some households could significantly increase profitability if they had a large amount of additional capital to invest, but may not be able do so with only small amounts of capital if financial frictions are severe. If poor households lack access to credit, they cannot borrow money to make the indivisible investment. Likewise, if returns to incremental savings are low, households may not be able or find it worthwhile to save up to make indivisible investments even when they are high yield. This paper uses a cash grant experiment in rural and semi-urban Uganda to evaluate the quantitative importance of investment indivisibilities in areas with low coverage by financial services firms. Regional capitals in Uganda are a natural environment in which to study the importance of access to investment capital because of the limited existence of formal financial services and the prevalence of micro-entrepreneurs.

Cash grants have become a popular approach to identifying the marginal returns to entrepreneurs (De Mel et al., 2008, 2014) and to poverty programs more generally (Blattman et al., 2014, 2016; Haushofer and Shapiro, 2016, 2018; Egger et al., 2019). While the existing literature has utilized randomized approaches, the innovation in this paper is to combine variation in potential grant size and a choice between lotteries that are comparable in their expected value. ${ }^{1}$ This allows us to condition grant size on the participant's choice of small or large lottery, and to observe whether indivisible investments are made for the group that selects into the high-risk lottery. The participant's choice between lotteries allows us to directly observe the characteristics of those most likely to choose riskier options and who expect larger returns from selecting the larger lottery (which in expected value is actually slightly smaller). We find that participants who choose the risky lottery are wealthier and have more business assets.

We relate the impacts of these grants to the predictions from a model in which agents face indivisible investment opportunities. Agents receive uncertain labor income, face risky indivisible investment opportunities, and vary in the productivity of such investments. Inspired by low observed levels of credit, we model stark financial conditions of no credit and a zero-interest saving technology. The calibrated model yields several empirical predictions for the behavior of agents offered the simulated lotteries. Those with high capital productivity and assets below what is needed for the indivisible investment are characterized by

\footnotetext{
${ }^{1}$ Specifically, we offer participants the option of choosing a lottery that pays off a small grant (roughly $\$ 100$ ) with a relatively high probability $(50 \%)$, or a smaller chance $(10 \%)$ of winning a much larger grant (roughly $\$ 500)$. The latter amounts to roughly 10 months of income for the median household. We also offer them the chance to delay payment by one month and earn 3 percent, a high interest rate and non-negligible amount of absolute interest (roughly 2 or 10 days of median income for the small or large grants).
} 
risk-loving behavior with varying levels of patience and impatience, due to high potential returns.

Consistent with this theory, we show that a substantial share of the population prefers the riskier option (27 percent). The risky option is preferred especially among high-saving, male, investment-oriented households. These participants are willing to accept a higher risk lottery with comparable (though slightly lower) expected payoff in order to have a chance at winning the investment capital necessary to invest and reach a state with higher wealth.

The endline results show a substantial increase in more divisible business and agricultural investments among grant winners at first endline (4 months out), and sizable land purchases for those who won the larger grant. Indeed, the point estimates seem to exceed the size of the grant. The results indicate that the full small grant was used for agricultural and business investment (primarily inventory), and the large grant was used mostly for land and larger business assets. By the second endline (18 months out), only the significant impacts on land and business assets persist.

No significant impact on either consumption or income is observed in either endline. However, the confidence intervals on income and especially consumption are quite wide, suggesting that the impacts are highly variable. Moreover, the data show strong appreciation in land prices ( $2 \%$ per month). Given the wide standard errors on estimates, we cannot rule out substantial rates of return on the grants. Indeed, the point estimates are positive and higher for the large grants once we account for the capital gains on land.

In our empirical analysis, we also make a small though important empirical innovation. We apply a seemingly unrelated regression (SUR) with the household budget constraint as the cross-equation restriction. The cross-equation restriction ensures that the coefficients "add up" in a budget constraint sense and the coefficients can be interpreted as the amount of the grant money spent in each category. This is in contrast to the unconstrained OLS results, which estimate an impact of unreasonably large magnitude on land investment. Empirically, the data cannot reject the restriction. Using Monte Carlo estimations, we show that such a constraint can increase efficiency, correct for bias, and yield reasonable and easily interpretable results, especially in the presence of measurement error and measurement bias. We view this innovation as potentially useful for other experimental work.

We then use our simple model together with the empirical findings to validate the model along certain dimensions and simulate the impacts of small- and large-scale financial interventions. Using only the prelottery data, we discipline the model parameters to match key moments of the distribution of income, assets, mobility, and lottery choices. We then show that simulated data is able to reproduce similarly large impacts of winning the large, risky lottery on investment. Monte Carlo regressions on simulated data also show that the model can reproduce the empirical finding of large impacts on indivisible investments that exceed the value of grant winnings.

In our counterfactual analysis, the quantitative impacts of relaxing financial frictions on aggregate development in the area depend critically on the elasticity of the supply of the investment good. Indeed, the model produces sizable impacts when capital is available at a fixed price. When allowed to borrow $25 \%$ 
of the value of their stock of capital (or land), households nearly double the quantity of that stock and increase their incomes by $23 \%$. In contrast, however, when capital is in fixed supply, the model produces an analytical neutrality result in response to relaxation of the borrowing constraint; the price of capital in general equilibrium simply adjusts.

The model's results relate closely to our experimental results, since general equilibrium effects may be quite relevant for an investment like land. We evaluate this claim, showing empirically that land values increased more rapidly in areas where lottery winnings were greater, which we interpret as the impact of increased demand for land from lottery winnings. In sum, despite the presence of large indivisible high-yield investments, aggregate impacts of financial service expansion may be less important for poverty reduction and development if such investments are land purchases with land in fixed supply.

Our paper contributes to the literature on several fronts. We add empirical and quantitative guidance to a macro literature on financial frictions and poverty traps. Banerjee and Newman (1993), Galor and Zeira (1993), and Piketty (1997) are examples of models with indivisibilities, where financial frictions lead to poverty traps. Later work showed that indivisible decisions, when embedded in quantitative models with intensive margins and mapped to the data, did not lead to macro multiplicities, but only micro poverty traps as in Buera (2009). This resulted in lower aggregate output (Buera et al., 2014; Midrigan and Xu, 2014) and slower convergence (Buera and Shin, 2013). These theories all lead to demand for financing but also risk. We contribute to these findings by showing the empirical importance of both indivisibilities and risk-loving behavior linked together, and using these empirical results to discipline their quantitative importance.

Other closely related papers present empirical evidence on poverty traps in developing economies. Balboni et al. (forthcoming) examine the impact of a uniform livestock asset grant in Bangladesh and show that the impact is an s-shaped function of the initial assets of the recipient. Our work complements theirs: we allow for an endogenous relationship between productivity and initial wealth, which would confound empirics based on the initial level of assets, so we focus instead on risk preference. Through our use of a risky versus safer lottery, we also examine whether some groups may experience differentially larger returns to investment. Relatedly, Banerjee et al. (2019) present empirical evidence that despite low average returns, microcredit does indeed break a poverty trap for "gung-ho" entrepreneurs, those with prior business experience who exhibit higher than average returns to business investment. In non-experimental settings, Lybbert, Barrett, Carter, and coauthors also examine livestock-based poverty traps empirically in a series of papers (e.g., Lybbert et al., 2004; Carter and Lybbert, 2012), and they highlight risk preference (Lybbert and Barrett, 2011). McKenzie and Woodruff (2006) present evidence from with observational data on Mexican microenterprises. These papers emphasize business investment and livestock as indivisible investments driving poverty trap dynamics. To this literature, we contribute novel findings on the role of land and capital gains in generating poverty traps. $^{2}$

Our simulations of the aggregate impacts of financial frictions are an additional contribution. Method-

\footnotetext{
${ }^{2}$ Although land is in principle divisible, whether property rights are customary or formal, it is generally divided into discrete plots both in its use and any transactions and titling.
} 
ologically, we contribute to an emerging literature using experiments in conjunction with macro development models (e.g., Buera et al., 2014; Bergquist et al., 2019; Donovan, 2020; Lagakos et al., 2018; Buera et al., 2020). ${ }^{3}$ While these papers use the results of RCTs to discipline simulated impacts of scaled policies in the macroeconomy, our paper is novel in using an experiment to actually test an existing theory of macrodevelopment and quantify its implications. We focus on financial services and illustrate that, even when indivisibilities can lead to micro-level poverty traps where financial services may seem particularly needed and powerful, their scaled impact can depend critically on the elasticity of the supply of the relevant capital.

The rest of the paper is organized as follows. The next section presents our simple motivating model. Section 3 summarizes our experimental methodology and data collection. Section 4 describes our empirical results. Section 5 calibrates the model to our data and simulates the macroeconomic consequences of credit injections and redistribution. Finally, Section 6 presents evidence on the importance of general equilibrium effects on land prices in the aggregate.

\section{Model and Motivation}

In this section, we develop a simple model to illustrate mechanisms through which the combination of high-yield indivisible investments and financial frictions can lead to both poverty traps and behavior that is risk-loving and impatient. This provides motivation for our empirical experiment. Although we focus on qualitative patterns of individual decisions here, the model is parametric, since it will be later used for quantitative analysis in Section 5.

\subsection{Set Up}

We discuss the preferences, income streams, and investment decisions of households in turn.

\subsubsection{Preferences}

Households have time-additive, log preferences over consumption:

$$
V_{t}=\mathbb{E}_{t} \Sigma_{t=0}^{\infty} \beta^{t} \ln c_{t}
$$

We assume that a fraction $1-p$ of them die each period and are replaced by an equal mass of newborn households with no initial wealth. Therefore, $\beta=\hat{\beta} p$ reflects time discounting, a product of the discount factor $\hat{\beta}$ and the survival probability $p$. The expectation is over realizations of death but also shocks to labor income, $e_{t}$, and capital income, $y_{t}$. (Here we loosely refer to capital income and capital to capture any investment income, but keep in mind that empirically, land will be the relevant investment good.)

\footnotetext{
${ }^{3}$ See Buera et al. (2020) for a review of this literature.
} 


\subsubsection{Income}

Labor income is a product of permanent and transitory components, both of which are stochastic. Specifically, we assume that

$$
e_{t}=\bar{e} \varepsilon_{t}
$$

where $\bar{e}$ is a permanent component and $\varepsilon_{t}$ are idiosyncratic, independently- and identically-distributed (iid), lognormal innovations with $\log$ mean equal to zero and $(\log )$ variance of $\sigma_{e}^{2}$.

Capital income is a function of the amount of capital $k_{t}$ and entrepreneurial ability $z_{t}$ :

$$
y(z, k)=z_{t} k_{t}^{\alpha}-\delta k_{t} .
$$

We assume $0<\alpha<1$ so that the production function exhibits diminishing returns to scale. The term, $\delta k_{t}$, is the maintenance expense associated with having $k_{t}$ units of capital. Like labor income, capital income is also stochastic, since $z_{t}$, in parallel fashion, also follows a stochastic process:

$$
z_{t}=\bar{z} v_{t}
$$

where $v_{t}$ are iid., lognormal innovations with mean zero and variance $\sigma_{v}^{2}$.

\subsubsection{Financial Environment and Investment Decisions}

Households choose their liquid assets and capital. While capital produces capital income, liquid assets $a_{t+1}$ earns an interest rate of $r$. In principle, liquid wealth can be negative but savings decisions are bounded below, since borrowing is limited by the value of available capital as collateral. We assume that households can borrow up to a multiple $\theta$ of this value

$$
a_{t+1} \geq-\theta P_{t} k_{t+1}
$$

Capital can be bought and sold at the price $P_{t}$, but, critically, to capture the indivisibility of investment in a simple fashion, we assume it is divided into discrete units of size $\underline{k}$ and can therefore only take on discrete values $k_{t} \in\{0, \underline{k}\}$.

Denoting the price of capital $P_{t}$, the household's budget constraint is:

$$
c_{t}+a_{t+1}+k_{t+1}-k_{t}=e_{t}+(1+r) a_{t}+z_{t} k_{t}^{\alpha}+(1-\delta) P_{t} k_{t} .
$$

One can reformulate the household's problem recursively with cash on hand, $l=e+(1+r) a+z k^{\alpha}+$ $(1-\delta) P k$, as the only endogenous state variable. The value function then becomes:

$$
V(l ; e, z)=\max _{c, a^{\prime}, k^{\prime}} \ln c+\beta \mathbb{E} V\left(l^{\prime}\right)
$$

subject to:

$$
c+a^{\prime}+P k^{\prime} \leq l,
$$




$$
a^{\prime} \geq-\theta P k^{\prime}
$$

and

$$
l^{\prime}=e^{\prime}+(1+r) a^{\prime}+z^{\prime}\left(k^{\prime}\right)^{\alpha}+(1-\delta) P k^{\prime} .
$$

We normalize $P$ to one in the initial steady state prior to interventions.

\subsection{Model Results: Poverty Traps and Risk Loving Behavior}

We first show how the model generates poverty traps and risk-loving lottery choices. We then summarize how the model motivates our experiment and empirics.

\subsubsection{Optimal Choices and Poverty Traps}

Poverty traps arise in the model due to the indivisible investment. One can show that the household will never invest if productivity is so low that the return from investing in capital is less than the return to saving in assets. That is, the household will only invest if the return to investing $k_{1}$ (the marginal return of the first indivisible unit of capital is highest) exceeds that of saving the same $\underline{k}$ :

$$
\mathbb{E}\left[z \underline{k}^{\alpha} \mid \bar{z}\right]+(1-\delta) \underline{k} \geq(1+r) \underline{k}
$$

The return to saving (right-hand side) is constant, whereas the return to investing (left-hand side) is increasing in $\bar{z}$. When this constraint holds with equality, it defines a lower bound $\bar{z}^{*}=(r+\delta) \underline{k}^{1-\alpha} \exp \left(-\sigma_{e}^{2} / 2\right)$ on entrepreneurial productivity such that for lower levels of $\bar{z}$, no investments are made. The poverty trap and risk-loving behavior we focus on is therefore characteristic of those with high entrepreneurial productivity and a desire to invest, a key finding we will examine empirically.

We now discuss the model's more interesting qualitative predictions with respect to poverty traps, savings behavior, and risk. We present simulated examples of optimal behavior for a particular value of $\bar{z}>\bar{z}^{*}, e$, and $k=0$ in Figure 1. We also set the parameters of the financial system such that households have no access to credit, i.e., $\theta=0$ or interest bearing savings, i.e., $r=0 .{ }^{4}$ (All parameters follow our later empirical calibration in Section 6.) Moreover, for easier exposition, we present the value functions and optimal policies (i.e., behavioral decisions) as functions of liquid assets, $a=l-e$, a simple transform of cash-on-hand. The four panels shows the value function (upper-left), capital choice (upper-right), liquid assets — or savings choice (lower-left), and consumption choice. For each panel, the minimum amount of assets needed to invest in the indivisible capital, $\underline{k}$, is critical, so we indicate it with the vertical, dashed, red line. (Though labeled $\underline{k}$ for simplicity, this line is actually $\underline{k}-e$ under the transform.)

The upper-left panel shows the value function increases with the level of liquid assets but in a very nonlinear way around the threshold, as we discuss below. The upper-right panel shows that if households' liquid

\footnotetext{
${ }^{4}$ These stark assumptions are simply illustrative at this point, but they will not be too far off from our empirical setting, where credit levels are quite limited and formal savings accounts bear no interest. We will maintain these parameter values for a benchmark in our quantitative work of Section 6.
} 
assets exceed the minimum threshold, then they invest immediately in the indivisible capital. All households would like to, but poorer households are unable to invest given the borrowing constraint.

Looking at lower panels, we see that savings (left) and consumption (right) decisions are non-monotonic, with both dropping around the investment threshold. At the threshold, savings drops to zero, as the household puts all available resources into the indivisible capital because of its higher return. Indeed, consumption also falls to nearly zero, indicating that the threshold asset level to invest is only slightly higher than the needed investment; households are willing to sacrifice consumption, when high yield investment opportunities are available. As assets increase beyond this threshold, however, consumption increases one-for-one as the marginal utility of present consumption exceeds the expected marginal utility of future consumption (which will likely have higher income because of the investment). Thus, households, though wealthy, are hand-to-mouth. ${ }^{5}$

The dashed blue line in the lower-left panel is the 45-degree line. The intersection of the savings policy function with this line defines a critical value of assets, $a^{*}$. Since the savings functions crosses the 45degree line from below, this intersection defines an unstable steady state but also characterizes poverty trap dynamics: a household with assets above $a^{*}$ will (in expectation) save up and increase its liquid assets over time to eventually invest in the high yield indivisible investment. In contrast, a household with liquid assets below $a^{*}$ will (in expectation) see its assets decline to the stable steady state at zero over time.

Looking at consumption decisions in the lower-right panel, one can see the importance of the threshold, which corresponds to a local peak in consumption. However, at asset levels below this peak, consumption is lower because assets are lower. At asset levels above this peak, consumption is lower despite assets being higher. Hence, households saving to invest display an apparent high level of patience, not because of an innate higher discount factor but because the household is saving to self-finance the high-yield indivisible investment in the future.

Finally, we return to the upper-left panel, to see how this behavior impacts the value function. Note that the slope of the value function reflects the marginal value of assets, which varies considerably. The marginal value of assets is highest just to the right of the threshold, given the low level of consumption. Indeed, to the right of this threshold, the value function exhibits the standard concavity in assets, reflective of the diminishing marginal utility of consumption implied by the assumed logarithmic utility function. However, to the left of the $\underline{k}$ threshold the function is convex, reflecting the declining consumption as assets approach the threshold level.

\subsubsection{Lotteries and Risk}

The convex region of the value function leads to a preference for risk which will motivate our empirical study. In the lottery experiments of the next section, we will offer a choice between four different lotteries: (i) a

\footnotetext{
${ }^{5}$ This nonmonotonicity in consumption with indivisible investment was emphasized by Kaboski and Townsend (2011), and such people in advanced economies were later coined the "wealthy hand-to-mouth" by Kaplan and Violante (2014) and Kaplan et al. (2014).
} 
"safe now" lottery that pays $\Delta^{S}$ with probability $\pi^{S}$ immediately; (ii) a "safe delayed" that pays off with 3 percent interest, i.e., $1.03 \Delta^{S}$, next period with the same $\pi^{S}$ probability; (iii) a "risky now" lottery that pays off $\Delta^{R}>\Delta^{S}$ but with only probability $\pi^{R}<\pi^{S}$; and (iv) a corresponding "risky delayed" lottery that pays $1.03 \Delta^{R}$ next period with the same $\pi^{R}$ probability. To assess these lotteries in the context of theory, we denote these four options as $S N, S D, R N$, and $R D$, respectively, and use these as superscripts on the value function to denote the value of choosing each lottery. ${ }^{6}$ As in our empirical experiment, the risky lotteries have a slightly lower expected payout, so typically risk aversion would push households to choose the safe lottery. However, the indivisible investment opportunity, together with the borrowing constraint, lead to this choice depending on available cash-in-hand (and therefore, in our simplified example, liquid asset) levels.

The value function of being offered the lottery, $V^{L}$, is then:

$$
V^{L}(l ; e, z)=\max \left\{V^{S N}(l ; e, z), V^{S D}(l ; e, z), V^{R N}(l ; e, z), V^{R D}(l ; e, z)\right\} .
$$

Figure 2 shows $V^{L}$ (black, solid line) relative to the original $V$ (dashed, black line) and how the optimal lottery choices vary by the level of assets. Clearly, since each lottery has nonnegative payoffs, $V^{L}$ exceeds $V$ at all points. However, the value of the lottery choice ( i.e., $V^{L}-V$ ) is greatest for a household whose assets are just below the threshold, since the lottery gives them the possibility of being able to quickly make the high-yield, indivisible investment.

Which lottery the household chooses depends on its asset levels, however. When the household already has enough liquid assets to invest, it chooses the safe now lottery, since investing is irrelevant and the value function is concave. Similarly, households just below the threshold choose the "safe now" lottery, since winning it yields enough to make the investment, it pays off with a higher probability, and it pays off now (so the investment can be made immediately). In the intermediate ranges, as assets get further below the threshold, the choice moves to the "safe delayed", "risky now", and "risky delayed" choices. When assets are low enough that winning the "safe now" lottery will not quite enable immediate investment, the "safe delayed" is chosen because delaying increases the available resources next period. For still lower levels of assets, the "risky now" is preferred, as the household is willing to take the lower odds of winning because only the higher

\footnotetext{
${ }^{6}$ The values of the immediate lotteries are simply:$$
V^{S N}(l ; e, z)=\pi^{S} V\left(l+\Delta^{S} ; e, z\right)+\left(1-\pi^{S}\right) V(l ; e, z)
$$

and

$$
\left.V^{R N}(l ; e, z)=\pi^{R} V\left(l+\Delta^{R} ; e, z\right)+\left(1-\pi^{R}\right) V(l ; e, z)\right]
$$

The delayed lotteries require defining continuation values conditional on winning the lottery, since current choices will anticipate future winnings. Define this for risk level $X \in\{S, R\}$ as

$$
W^{X D}(l ; e, z)=\max _{c, a^{\prime}, k^{\prime}} \ln c+\beta \mathbb{E} V\left(l+\frac{1.03 \Delta^{X}}{1+r} ; e, z\right)
$$

subject to the budget constraint and law of motion, constraints (2) and (4), respectively. The value of the delayed lotteries are then

and

$$
V^{S D}(l ; e, z)=\pi^{S} W^{S D}(l ; e, z)+\left(1-\pi^{S}\right) V(l ; e, z)
$$

$$
V^{R D}(l ; e, z)=\pi^{R} W^{S D}(l ; e, z)+\left(1-\pi^{R}\right) V(l ; e, z) .
$$
}


payout will enable it to invest. Again, at even lower levels, the "risky delayed" is preferred, when winning the "risky now" would still not enable immediate investment. Finally, at the lowest level of investment, the "safe now" is again preferred. When the household is so poor that even winning the highest payout of the "risky delayed" would not be enough for it to be close to investing, so the investment opportunity is effectively irrelevant, and the value function is locally concave.

\subsubsection{Experimental and Empirical Motivation}

In summary, the model shows a connection between high-yield, indivisible investments, financial frictions, and poverty traps. The model motivates our experimental design in the next section and also leads to testable predictions that guide our empirics:

- high productivity households may have higher savings to eventually finance indivisible investment opportunities;

- risk-loving lotteries can be chosen to help finance indivisible investments;

- those choosing risk-loving lotteries are high productivity; and

- high productivity households may exhibit either patience or impatience in their lottery choice.

\section{$3 \quad$ Field Experiment}

We conduct a lottery experiment in the field that mirrors the theoretical lotteries of the previous section in order to empirically estimate the extent to which indivisibilities in investment opportunities may impact household income. This section provides details of the design and implementation of our lottery experiment as well as our data collection and measurement. ${ }^{7}$

\subsection{Experimental Design}

To draw our sample, we worked with a prominent microfinance bank that was hoping to expand services. We identified three geographically dispersed, underbanked districts where marginal populations lacked financial services: Ntungamo, Ibanda, and Kagadi. ${ }^{8}$ All three are regional capitals but with populations of roughly 20-30,000. The surveyed neighborhoods are best described as small, peri-urban and semi-urban. Using a neighborhood census of each of the the targeted neighborhoods, we randomly selected a stratified sample of 1,048 participants, each from a distinct household. ${ }^{9}$ We oversampled entrepreneurs and those who lacked formal financial services (i.e., had no formal loan or savings account at the time). All three districts are evenly represented in the sample: 350 participants come from Ntungano, 349 from Ibanda, and 349 from Kagadi.

\footnotetext{
${ }^{7}$ This experiment was pre-registered, AEARCTR-0002217

${ }^{8}$ We piloted a related project in Mpigi in order to evaluate our survey instruments and other protocols.

${ }^{9}$ Neighborhoods were randomly selected by placing a grid across each city and randomly selecting gridpoints overlaid on a map of each city. Gridpoints that fell in manufacturing zones, parks, or other unpopulated areas were omitted. We then used a census of the neighborhood around gridpoints. From the census, we selected a sample stratified by use of formal financial services, gender, head of household, expressed desire for a savings account, and occupation (entrepreneur, salaried employee, or farmer). We also stratified over gender and whether or not the recipient was a head of household.
} 
The timing of the experiment was as follows. In October and November, 2015, we conducted a baseline interview of households including questions on their household demographics, income, consumption, agricultural and business activities, assets, borrowing and savings, and hypothetical questions on income, investment, risk and time preferences. At the end of the survey, all households were offered a free, zerointerest formal savings account at a microfinance bank with a local branch. In February and March of 2017, approximately 16 months after participants received their savings accounts, we conducted the midline survey, where we resurveyed participants about their updated responses to selected baseline questions and then implemented the cash lottery experiment described below. A comprehensive first endline survey was conducted in June and July of 2017. Those who had chosen to receive delayed payments were surveyed a month after the impatient sample who received non-delayed payments, so that all participants were surveyed 4 months after receiving their cash grants. The first endline survey consisted of similar questions to the baseline, but included additional questions about how recipients had utilized their grant money. A second endline, meant to track longer-term household outcomes and observe changes in grant effects over time, was conducted between September and November 2018, approximately 18 months after cash grant receipt.

The experiment at midline included a choice that the participant was asked to make between participating in two lotteries: (i) a 50 percent chance of winning a grant of 350,000 Ugandan shillings or UGX (\$98 based on an exchange rate of 3,570 UGX $=1$ USD in February, 2015) or (ii) a 10 percent chance of a grant of 1,700,000 UGX (\$476). The sizes of grants were chosen based on baseline questions about desired investment amounts and demand for credit. ${ }^{10}$ As in the model of the previous section, the second lottery had both higher risk and a lower expected value (\$47.60 vs. $\$ 49.00)$. The participants were visually primed through "practice" lotteries in order to assist them with understanding probabilities and the lottery. Finally, participants were given the choice to receive their grants (conditional on winning) via mobile money either the following day or to delay payment for 30 days in return for 3 percent interest. Our use of mobile money and a minimum of one-day delay was designed to limit differential perceived risk in whether they would actually receive funds since no one received cash immediately in hand. After asking questions about how they would use their grants, the lotteries were run using random number generators and tablets, where participants could be shown their outcomes immediately.

Table 1 shows the lottery choice preferences of the sample. 766 people ( $73 \%$ of the full sample) chose the small grant. Of these, 144 people ( $14 \%$ of the full sample) chose to delay the payment by a month in return for a larger payment, while the remaining $622(59 \%)$ chose to receive the payment the next day. The choice of the small, less risky lottery with no delay was therefore the most common. The high level of impatience is perhaps surprising given the high foregone rate of return (43\%, annualized and compounded) and non-negligible absolute return (equivalent to 2-10 days of income for the median household, depending on the size of the grant). Despite its riskiness and lower expected payout, 282 people ( $27 \%$ of the full sample) chose the lottery for the larger grant. This is again quite a powerful result since the large lottery had a lower

\footnotetext{
${ }^{10}$ Specifically, we asked at baseline whether they would invest if they had access to credit, and how much they would need to make their desired investment. The sizes of the grants approximately match the 25 th and 75 th percentile responses
} 
expected value. As shown in the theory of high-yield indivisible investments in Section 2, participants may be willing to accept higher risk lotteries in order to enable a large, high return investment.

In the context of the model, we expect some individuals to be patient, i.e., those for whom the higher payoff from delayed payment enables the indivisible, high-yield investment sooner. This patience may be among those choosing either the safe or risky lottery. (Recall the RD and SD regions in Figure 2.) Of those who chose the riskier lottery for the larger grant, 78 participants ( $7 \%$ of the full sample) were patient and willing to wait a month for a larger payout, while 204 (20\%) were impatient. Thus, among those who were risk-loving about 1 in 4 was patient, while about 1 in 5 was patient among those who chose the small lottery.

Knowing that the larger grant was less likely to pay out and correctly anticipating that it would also be less popular, we increased the actual probability of winning the larger grant to $30 \%$ - it ended up being $28 \%$ - relative to the $10 \%$ probability communicated to participants, in order to increase the sample size of winners. Table 2 presents the number of lottery winners in each category. We present the number of winners as a percentage of the people who made the choices. Of the 766 who chose the smaller, less risky lottery, 374 won the lottery for a win rate of $49 \%$. This win rate does not vary across the patient or impatient. Of the 282 who chose the larger lottery, 78 won, for a win rate of $28 \%$. An even higher percent (30\%, or 62 recipients in total) won among the risk-loving and impatient, a group of special interest, since these are the most likely to desire loans. Because of budget and sample size limitations, we did not randomize any participants into winning the small grant if they lost the large grant, or into winning the large grant if they lost the small grant.

The lotteries themselves yield our experimental variation. The lottery choices are of course endogenous, so we control for lottery choice in all specifications. Conditional on the lottery choice, the lottery outcomes were random, however. As discussed in the following Data section, Tables 3 and 4 confirm balance between the treatment (grant recipients) and control (non-recipients) for both the small and large lotteries.

\subsection{Data}

We collected data over four survey rounds: baseline, midline, first endline, and second endline. For several of the financial outcomes, we collect data in a multistep process in order to improve measurement. First, we use questions about subcategories in order to prime the respondent about the many different specific sources of income, expenses, assets, etc. that they may have had. Second, we summed the subcategories together to get the total value. Third, we confirmed with the respondent whether the aggregate category reflects their perception. For example, income is collected as "typical monthly income" (revenues net of costs) using detailed questions about typical monthly revenues on subcategories, i.e. business, crop, livestock, and labor income, as well as direct questions on aggregate income and following up to see whether the participant viewed the aggregate or sum of the components as a better predictor. We ask for the respondent's income separately from household income because the former may be measured with less noise. The Data Appendix describes these steps and measures in more detail for each of the other categories. 
Using these data, and guided by the components of a typical household budget constraint, we construct seven variables as our primary outcomes of interest in the endline: consumption, income, savings, net credit, and total physical assets (also disaggregated into business assets, agricultural assets, and land). The distinction between flows and stocks is important from a theoretical standpoint. We measure income and consumption as flows, and savings, assets, and net credit as stocks. Consumption is constructed as total spending on regular household expenditures (food, fuel, airtime, and any irregular expenses, like school, hospital or marriage fees) since midline plus value of home durables. ${ }^{11}$ Income is monthly flow of realized household income (wages, business profit, livestock profit, and crop profit). Savings reflects current total levels at each respective endline. Net credit is current debt less any lending to others that the household expects to be paid back. Business assets includes level of inventory and non-inventory assets. Agricultural assets is the total value of agricultural durables, such as tools and machinery, plus current livestock.

Finally, land is the value of land owned, but we must address an important issue around the prices of land. As with many peri-urban areas in developing countries, land values in Uganda increased significantly over time (and we find that many of the participants who won the large grant purchased land with the money that they won). This was not anticipated, and so land prices, land quantities, and land purchase values were not separately collected. However, we are able to correct for land values, land prices, and land purchases by imputing capital gains using control households. That is, we calculate the increase in land prices using the land values of control households.

Specifically, we estimate the amount of land value appreciation in each district. While increases in treatment household land values were likely to result both from purchases with the capital they won through the grant and land appreciation, increased land value among the control households on average suggests land value appreciation. To estimate the amount of land appreciation in each district, we construct capital gains estimates using ratios of reported land values across survey rounds for control group households. We use the estimated appreciation to adjust our total investment and land purchase amounts downward, reflecting that the land value increased since the purchase. Moreover, we use the capital gains to estimate returns on land purchases.

Land value appreciation may either be a result of general local price increases, or from increased demand for land as a result of increased availability of capital in the area from a neighbor's winnings. ${ }^{12}$ In this section, we calculate the total amount of land appreciation in each district. Proximity to treatment households who purchased land could also have increased the value of the control households' land. We calculate the percent of the increase in land value that can be attributed to nearby households receiving a grant and purchasing land in Section 6, Table 14 using instrumental variables techniques. On average, we find that roughly $3 \%$

\footnotetext{
${ }^{11}$ We include household durables in our measure of consumption. This differentiates household durable spending from spending on other assets, which we include in the investment category because it may lead to positive income returns. Data on durables were not collected at midline, so we simply add the stock of durables to the flow of consumption. This should lead to no issues with our application of the budget constraint (see next section) as long as midline durables were balanced.

${ }^{12}$ The regions of Uganda along the western border have seen an expansion of the oil industry, and government granting of lands to the search for oil has reportedly displaced many original inhabitants and driven up land prices more generally in Uganda. See Gochberg (2021).
} 
percent of land appreciation between midline and the second endline was a result of the award of grants in the neighborhoods.

To derive the total capital gain in land value over time, we sum land values across all control households in each district $d$ at endline over the sum of the same set of control households' land values at baseline. We allow capital gains $(\phi)$ to vary by district. We do this for both the first and second endline and adjust the ratios to reflect appreciation solely between midline and each respective endline. Specifically, for control households in a given $d$ district:

$$
\phi_{d}=\left(\frac{\sum_{i} \operatorname{land}_{i}^{e}}{\sum_{i} \operatorname{land}_{i}^{b}}\right)^{\frac{x}{y}}
$$

where $d \in\{$ Ntungamo, Ibanda, Kagadi $\}, i$ denotes household, $x$ denotes time in months between midline and the relevant endline, $y$ denotes time in months between baseline and the relevant endline, $b$ specifies baseline, and $e$ specifies the relevant endline. Table A.1 in the Appendix shows the calculated capital gains ratios. We find that land values appreciated at a rate of approximately $2 \%$ per month. We construct new capital gains-adjusted land ${ }^{\dagger}$ values for all households in each district $d$ at each endline:

$$
l a n d_{i d}^{\dagger}=\left(\frac{1}{\phi_{d}}\right) \operatorname{land}_{i d}
$$

Given the observed $2 \%$ average monthly appreciation, we show that spillover effects of grants on land value account for only a small proportion of overall land appreciation. In general, land values increased by $41 \%$ between midline and second endline (a period of 18 months), and we estimate that the grants themselves increased land values by $3 \%$ over the same period. Thus, a one-time injection of capital through the grants accounted for only about $7 \%$ of total land appreciation. This is natural given the small-scale of the experiment, and implies that, on their own, peri-urban villages in Uganda already experience high levels of land appreciation over time.

We return to midline data to examine sample characteristics and experimental balance between treatment and control. Again, participants self-selected into either the low-risk and high-risk lottery, but the realization of whether they won was random. We check balance across 19 baseline and midline outcome and demographic measures within the sample. Table 3 presents the balance results for those who chose the smaller, low-risk lottery, whereas Table 4 presents the balance results for those who chose the larger, high-risk lottery.

Before comparing treatment and control, note first some sample characteristics. The average midline income of 362,000 UGX translates to $\$ 101$, and households average five members. Households are therefore quite poor, and grants are sizable relative to income. Well over sixty percent of households are farmers, and about half are women. Financial intermediation is low with only about one-third of households having loans, and roughly ten percent having savings in formal accounts. The overall levels of consumption, income, and savings have implications for the demand for financial services. Though few utilize their zero interest formal savings accounts, the data show a substantial underlying level of savings that could indicate a demand for financial services. Specifically, comparing the levels of savings to that of consumption, the average household 
savings is about 7 weeks of average household consumption. We also find large increases in savings from baseline to midline and substantial demand for credit for investment (see Table A.2). ${ }^{13}$

Now comparing treatment and control, balance is quite good. For the total of 38 outcomes across the two tables, we would expect between 1-2 variables to be significant at a 5 percent level based on type I errors, but indeed none are statistically significant at the 5 percent level, and only one is significant at the 10 percent level (households winning small grants tended to consist of a slightly smaller number of adult females, 1.1, as opposed to 1.2 for the low-risk control). Thus, the balance is quite good. Still there are a few variables in which the differences appear to be potentially economically significant. In Table 3, the average monthly income is roughly 25,000 UGX less among the low lottery treatment "winners" relative to the control, and savings is 20,000 UGX higher, which are both small relative to the size of the 350,000 UGX grant received but not negligible. Similarly, in Table 4, we see that average monthly income is 50,000 UGX more in the high lottery treatment relative to the risk loving control and likewise midline savings is 70,000 UGX more, which is small but not completely negligible compared to the 1,700,000 UGX. Land values as well are 2,950,000 UGX larger (or $23 \%$ higher) in the large lottery treatment group relative to the high-risk control, though this difference is not statistically significant. This is part of our motivation in controlling for baseline and midline differences in our endline analyses. We find similarly good balance among those receiving the grant and those not receiving the grant when partitioning by the choice of early or delayed reception. ${ }^{14}$

Finally, we note that, despite our careful attention to accuracy, expenditures (i.e., consumption + savings + investment) between baseline to midline exceed available resources (i.e., income + change in borrowing) substantially, by a factor of 2.2. There are multiple possible reasons for this: (i) expenditures may be more salient than income, (ii) expenditures may be too salient so that people remember expenditures as being more recent than they truly are, (iii) land appreciation may be truly higher for those who purchased land, and (iv) people may over-perceive the appreciation of their own land purchases, a type of revealed preference or bias in their expectations. We highlight this bias between expenditures and income because it will be relevant for our measurement of the impacts of grants in the next section.

\section{Empirical Methods and Results}

The model predicts that entrepreneurs who have a large, indivisible investment opportunity are more likely to accept a risk-loving large lottery, and that these investments may increase their income over time. In this section, we test the extent to which we see these results in our participants. We find that participants

\footnotetext{
${ }^{13}$ The lack of use of the formal accounts may have several causes: low trust in formal accounts as currently offered, the fact that the accounts are zero interest, or that traditional formal accounts are simply not convenient enough to use, even when offered free of charge. This may be because of the costs associated with transactions like transportation costs, or a mistrust of institutions. Novel approaches like savings groups or cell phone-related savings vehicles may therefore be more appropriate for meeting this underlying demand.

${ }^{14}$ We also check balance on these same 19 measures between the retained and attrited sample for both the retained lowrisk group relative to the attrited low-risk group and the retained high-risk group relative to the attrited high-risk group. In general, balance is good, and we are not concerned about non-random attrition. We find significant differences only on age and correspondingly age ${ }^{2}$, between the retained low-risk group and the attrited low-risk group. We include age and age ${ }^{2}$ as demographic controls in our outcome analyses along with household composition variables, which includes the number of adult females, the one variable that is significantly different between treatment and control at the ten percent level.
} 
choosing the large, risky lottery tend to be people who own more assets, whose wealth has increased quickly since the baseline, and are more wealthy in absolute terms.

When they win, participants in small, low-risk lotteries tend to make more transitory investments in business inventory, savings, and livestock, while winners of larger, high-risk lotteries tend to make larger investments in land. This investment in land among large grant winners is our most salient and surprising result. Assets remain significantly higher for the large grant winners 18 months after the grant is awarded.

We find no evidence of direct income gains from winning either grant, whether in the short run or 18 months later. However, standard errors are large, and we cannot rule out substantial rates of return on investment (which also incorporate the sizeable capital gains on land). This is particularly true for large grant winners given their propensity to invest in land.

\subsection{Determinants of Lottery Choice}

The model predicts that participants with a large, lucrative investment opportunity are more likely to select the large lottery. We examine the significant predictors of the lottery choice in our data. We first run simple OLS regressions to test whether the characteristics that the model predicts matter in the risk decision are in fact empirically related to the risk decision. We run the OLS regressions:

$$
D_{i}^{m}=\beta P_{i}^{m}+\gamma X_{i}^{m}+\varepsilon_{i}
$$

and a LASSO specification in which we regress:

$$
\begin{aligned}
& D_{i}^{m}=\sum_{j=1}^{285} \beta_{j} P_{i j}^{m}+\varepsilon_{i} \\
& \text { s.t. } \sum_{j=1}^{285}\left|\beta_{j}\right| \leq s
\end{aligned}
$$

where $D_{i}^{m}$ is the decision of household $i$ at midline $m$ (e.g., a dummy for the risky choice, a dummy for the impatient choice) and $P_{i}^{m}$ are the midline predictors on which we test for significant differences between those choosing the safer lottery relative to those choosing the riskier lottery, as well as the impatient relative to the patient. $X_{i}^{m}$ is a vector of household-level demographic controls: household income, age, age ${ }^{2}$, number of adult females, number of adult males, number of children, as well as dummies for gender and whether the respondent is the household head. In the OLS specification, we first test whether each predictor $P_{i}^{m}$ is statistically significantly correlated with the lottery decision unconditionally, and second whether the predictor is correlated with the lottery decision conditional on the set $X_{i}^{m}$ of demographic characteristics. LASSO imposes the condition $\sum_{j=1}^{285}\left|\beta_{j}\right| \leq s$ for 285 covariates and a constant $s$, which dictates the level of constraint (Tibshirani, 1996). ${ }^{15}$ Table 5 presents statistically significant predictors of the risky lottery choice in the OLS regression. ${ }^{16}$ Predictors also selected by the much higher dimension LASSO regression

\footnotetext{
${ }^{15} \mathrm{~A}$ list of the full set of 285 covariates included in LASSO is available on request.

${ }^{16}$ The full list of covariates in which we test for significant differences between the high-risk group and low-risk group is in Table A.2 in the Appendix. The point estimates in both Table 5 and Table A.2 are from the unconditional specification of Equation 7, i.e. without $X_{i . m}$. The estimates conditional on $X_{i . m}$ are available by request.
} 
are designated with an asterisk.

Recall that the model indicated that those who choose the risk-loving lottery do so to finance investment, have high productivity, and may have higher savings as they increase wealth for self-financing purposes. Consistent with the model, the risk loving choice is associated with a pre-existing interest in investing. A significantly (6 percentage points) greater fraction of the participants who chose the large lottery report that they could increase their income if they had access to credit. Moreover, a significantly larger (4 percentage points) fraction wanted to invest an amount greater than $\$ 100$, the size of the small grant. Finally, a significantly ( 7 percentage points) larger fraction indicated that they would use credit for business investment. These predictors are significant at the $5 \%$ level in the OLS regression. The indicator for whether a household would use credit for business investment is also selected by LASSO. Thus, it appears that, at least for some, the demand for the risky lottery could be driven by a desire to invest, although quantitatively the numbers are small in explaining the choice.

Consistent with the model, those who selected the large lottery tended to have higher incomes. They had significantly higher (40 percent) crop income, significantly higher (13 percent) consumption, and significantly larger (20 percentage points) growth in consumption from baseline to midline. ${ }^{17}$ Crop income level was also selected by LASSO. Risk lovers tended to have higher crop income both in absolute terms and as a fraction of their total income, perhaps suggesting that those with higher levels of home production are more willing to take on risk.

We also find suggestive evidence that the risk loving were wealthier and that they experienced faster increases in their savings and wealth. Those who chose the risky lotteries were somewhat wealthier, a per adult equivalent difference of about 95,000 UGX (\$27) in total wealth (assets plus savings), and 101,000 UGX (\$28) in net wealth (assets plus savings minus debt) - approximately 30\% of average monthly income. After accounting for an average of 3.6 adult equivalents in the household, these differences are somewhat smaller than the size of the small grant and are only marginally significant at a 10 percent level.

Those who chose the risk-loving lottery did, however, have 28 percent more business assets and hold a higher fraction ( 5 percentage points) of their total wealth in business assets. The higher growth in wealth and savings before the midline is even more striking. Between baseline and midline, the risk loving experienced significantly larger increases in total wealth (500 percentage points), total savings (400 percentage points), and net wealth (1300 percentage points). Thus, the accumulation of assets seems to be a strong predictor of the choice of the large lottery. ${ }^{18}$

Finally, demographics are important in determining the risk choice. The risk-loving tend to be men, older, and heads of households, and come from larger households with more adult males. Somewhat surprisingly, those with more children also tend to be more risk-loving. A natural question is whether the financial

\footnotetext{
${ }^{17} \mathrm{On}$ average, incomes increased significantly between baseline and midline. This may be due to seasonal fluctuations in measured monthly income or seasonal variations in the components of income (crop income was especially high, while business income was lower).

${ }^{18}$ These percentage point changes are large because of the very low base levels of wealth in the sample: $40 \%$ of the sample has 0 or negative (because of loans outstanding) net wealth at baseline. Before taking logs, we set any negative or 0 values equal to 1 Ugandan shilling.
} 
predictors are ultimately driven by the demographics. For example, if men are both more risk-loving and have a higher propensity to invest or accumulate assets, then perhaps the accumulation of assets is no longer predictive after controlling for gender. We analyze this by looking at the same predictions but controlling for household demographics. ${ }^{19}$ The findings are largely robust. One exception is the level of savings is no longer a predictor of risk-loving, once we add income as a control. ${ }^{20}$

In sum, those whose wealth increased quickly between baseline and midline and those who expressed a pre-existing interest in investing were more likely to choose the high-risk lottery. Risk lovers also tended to have higher crop income, both in absolute terms and as a proportion of their overall income. These predictors are robust to the inclusion of demographic controls. LASSO selects three of the predictors shown to significantly predict risk preference in the OLS specification: monthly crop income level, an indicator for whether a household expressed an intent to use credit for business investment, and the number of people in the household. LASSO's selection underscores the importance of these attributes for predicting risk-loving behavior, and supports the hypothesis from the model that a pre-existing business investment is important for the choice between lotteries.

\subsection{Impact of Grants on Investment, Income, and Consumption}

The theory also has predictions for the use and impacts of winning lotteries, namely that those who win large lotteries should make large investments and increase their income. To evaluate the impacts of winning, we start with OLS regressions to estimate the impact of the large and small grant on the elements of the household's budget constraint at endline: consumption, savings, business assets, (capital gains-adjusted) land value, agricultural assets, income, and credit. For each $i$ household in district $d$, we regress:

$$
Y_{i d}=\beta_{0}+\beta_{1} W i n_{i}^{m}+\beta_{2} W i n_{i}^{m} * D_{i}^{m}+\beta_{3} D_{i}^{m}+\rho_{1} Y_{i}^{b}+\rho_{2} Y_{i}^{m}+\gamma X_{i}^{m}+\lambda_{d}+\varepsilon_{i d}
$$

where $b$ specifies baseline and $m$ specifies midline. $D_{i}^{m}$ reflects the household's lottery decision (risk loving or not), $W i n_{i}^{m}$ denotes whether the household won a lottery (small or large), and their interaction, $W i n_{i}^{m} * D_{i}^{m}$, is the additional effect of winning the risky lottery specifically. In this model, $\lambda_{d}$ are district fixed effects and $X_{i}^{m}$ is a vector of household-level demographic controls: patience, household income, age, age ${ }^{2}$, gender, household head, number of adult females, number of adult males, and number of children. ${ }^{21}$ We winsorize to the 5 th and 95 th percentiles. Because measurement error is an important consideration, rather than focusing on changes in consumption, savings, asset levels, income, and credit, we look at endline levels conditional on baseline and midline levels ( $\rho_{1}$ and $\rho_{2}$ ), consistent with the prescriptions in Bruhn and McKenzie (2009).

Our primary coefficients of interest are $\beta_{1}$ and $\beta_{2}$, where $\beta_{1}$ estimates the effect of winning the small lottery and $\beta_{2}$ estimates the additional effect of winning the large lottery. The total effect of winning the

\footnotetext{
${ }^{19}$ Table available on request.

${ }^{20}$ Though the theory is more ambiguous, we also test for significant predictors of the impatient versus patient, but find few differential characteristics. We control for patience in the remainder of our analyses, but do not interact the lottery outcome with time preference.

${ }^{21}$ Recall that all midline data are collected immediately prior to the random allocation of the cash grant treatment.
} 
large lottery (relative to the risk loving control) is therefore $\beta_{1}+\beta_{2}$, and we conduct $F$ tests on the sum. Based on the model, we expect to see impacts of the large grant on large assets, in particular, as households use the proceeds of the lottery to invest. For small lottery winners, we may expect transitory impacts on savings (or other divisible investments that perhaps mirror savings, such as inventory and livestock) while households accumulate additional funds to invest in a large asset or for those who simply smooth out small winnings before returning to poverty traps.

Our OLS approach, standard in the treatment literature, considers each outcome as an independent regression. However, basic adding up implies that the estimation equations are not independent but governed by a common budget constraint. That is, the following simple budget constraint should hold:

$$
\Delta C+\Delta S+\Delta K=x * \Delta Y+\Delta B+\text { Grant }
$$

where $C$ is consumption (including purchases of home durables), $S$ is savings, $I$ is investment (business assets + land + agricultural assets), $Y$ is income, $B$ is net credit, and $\Delta$ indicates the treatment difference, i.e., treatment minus control. ${ }^{22}$ We use $x \in\{4,18\}$ to denote the number of months between midline (the time of grant allocation) and the relevant endline, since income is measured as a monthly flow.

We therefore run a seemingly unrelated regression (SUR), which has three advantages. First, it allows us to impose a cross-equation restriction on the coefficients associated with the household's budget constraint. Second, it allows us to account for the correlation in error terms across equations that the constraint implies. Both of these improve efficiency, if they hold. Third, the cross-equation restriction yields coefficients that are sensible from a budget standpoint, where the increase in spending across categories does not exceed the amount of the grant.

The SUR uses the same basic specification as in Equation (9), with the constraint as a cross-equation restriction on the components of a household's budget. Specifically, we apply this restriction across the coefficients on Win $_{i . m}$ :

$$
\beta_{1 . c o n s}+\beta_{1 . s a v}+\beta_{1 . b u s}+\beta_{1 . l a n d^{\dagger}}+\beta_{1 . a g}-x \beta_{1 . \text { income }}-\beta_{1 . \text { credit }}=350,000
$$

And this restriction across the coefficients on $\operatorname{Win}_{i . m} * D_{i . m}$ :

$$
\beta_{2 . \mathrm{cons}}+\beta_{2 . \mathrm{sav}}+\beta_{2 . \mathrm{bus}}+\beta_{2 . \text { land }}^{\dagger}+\beta_{2 . \mathrm{ag}}-x \beta_{2 . \text { income }}-\beta_{2 . \mathrm{credit}}=1,350,000
$$

where 350,000 UGX is the amount of the small grant, 1,350,000 UGX is the additional amount of the large grant, and $x \in\{4,18\}$ denotes the number of months between midline and the respective endline, which is applicable to the coefficient on monthly income. All other outcome variables are in levels. The adding up condition allows us to precisely model how households may have spent the grant, and so we use the SUR

\footnotetext{
${ }^{22}$ This can be derived by our theoretical model by defining $Y_{t}=e_{t}+z_{t} k_{t}^{\alpha}-\delta k_{t}$ and recursively iterating on the budget constraint, equation (1) from midline to endline. Replacing the lower case notation with capital letter notation yields $\sum_{t=m}^{e} C_{t}+$ $A_{e}+K_{e}=\sum_{t=m}^{e} Y_{t}+A_{m}+K_{m}+$ Grant. We further break out net assets into gross savings and gross debt, i.e, $A_{e}=S_{e}-B_{e}$. Then differencing this between treatment (winners) and control (non-winners), and using the fact that $E\left[A_{m}+K_{m}\right]$ is equal for winners and non-winners because of randomization, yields equation (10). We will further evaluate this constraint from the context of simulated data from our calibrated model and measurement error in Section 5.2.
} 
estimates to calculate the average percentage of the small and large grant spent on each budget category. Under the SUR specification, we also conduct $F$ tests on the linear combination $\beta_{1}+\beta_{2}$, the coefficients which are constrained by the cross-equation restriction.

\subsubsection{Short Term Results}

Table 6 and 7 present the results at first endline for the OLS and SUR regressions, respectively. Focusing first on the OLS results in Table 6, we find four results of keen interest. First, small lottery winners increase small investments and perhaps savings. The point estimates of 237,000 UGX on business investment and 156,000 UGX on agricultural investment more than account for the 350,000 UGX winnings and are significant at the 5 percent level. There is perhaps some evidence to support an increase in savings as well, where the point estimate of 46,000 UGX is significant at a 10 percent level. The actual assets tend to be inventories for business and livestock for agriculture (see Table A.5 in the Appendix) so in the context of our theory, they could be conceptually grouped with savings. Second, large grant winners experience an enormous increase in land. The point estimate of 4,792,000 UGX is significant at the 1 percent level. The coefficient is quite large (amounting to over $\$ 1400$, more than annual income). However, careful study of the result shows that it is not driven by a handful of outliers (recall that we winsorize the data). Indeed, $35 \%$ of large grant winners report purchasing land between the first and second endline. Third, puzzlingly, the differential impact on land for large lottery winners is much more than the incremental winnings of the large lottery $(1,350,000$ UGX). Fourth, and related, the increase in land cannot be easily explained by a reduction in consumption, an increase in borrowing, or an increase in income that may have resulted from the winnings. Indeed, despite the increase in investment, we find no significant impacts on income from either the small or large grant, which adds an additional puzzle to the OLS results.

The unrealistically large OLS estimates of investment in land based on reported land values suggests that there may be bias in reporting of land values, particularly among those who purchase land. Our survey asked households for the estimated value of their land as of the survey date. There are at least three potential reasons that land values may have been overstated by new land owners. First, it may be that the more productive use of the land by the purchaser increased the value of the land. Second, there may have been faster land appreciation in the local area than in the region overall over the period, increasing the value of the land to far beyond the price the household paid, even after regionally adjusting for capital gains regionally. Finally, there is selection; households that purchased are naturally those that have higher intrinsic valuations of the land. The SUR regressions allow us to constrain the increase in value of the land to within the budget constraint rather than allowing the fast land appreciation to impact the coefficient results. This discipline of the data is an important feature of the SUR model and provides us with a better understanding of the lumpy investment households make in land purchases.

Turning to the SUR results in Table 7, we see how the SUR estimation adds clarity to these puzzles. Note first that the point estimates on those who won the (small) lottery are essentially unchanged but the 
standard errors are smaller. Second, the point estimate on land for large grant winners is now of a reasonable magnitude relative to the size of the grant and more precisely estimated. We estimate that the differential impact of the large grant is an incremental 1,523,000 UGX (significant at the 1 percent level) in land value. The total effect on land for large grant winners is 1,238,000 UGX (also significant at the 1 percent level), or $73 \%$ of the value of the large grant. Third, the model does not reject either of the cross-equation constraints. The budget constraint imposed across the coefficients on winning the large lottery is marginally rejected (significant at the 10 percent level), something that we explore further in Section 5 and find reasonable given our empirical measures. As we discuss in Section 5.2, the model results support the use of a cross-equation budget constraint. Finally, we continue to detect no significant positive impact on income, which is at odds with what the theory predicts.

We do find a positive impact on income for the large grant winners, but with a large standard error. Given the positive point estimate and the sizable capital gains we measured, investments may still yield considerable returns. To examine this, we calculate returns on investment (ROI). We measure investment as the sum of the coefficients on business assets, capital gains-adjusted land value, and agricultural assets in the SUR model. We calculate returns as the coefficient on monthly income flow plus monthly capital gains from land. Specifically, we calculate annual returns for those winning the small grant as: ${ }^{23}$

$$
R O I_{S}=\left(\frac{\left(\phi^{\frac{1}{x}}-1\right) \beta_{1 . l a n d^{\dagger}}+\beta_{1 . \text { income }}}{\beta_{1 . \text { business }}+\beta_{1 . l a n d^{\dagger}}+\beta_{1 . \text { agriculture }}}+1\right)^{12}-1
$$

And correspondingly for the large grant:

$$
R O I_{L}=\left(\frac{\left(\phi^{\frac{1}{x}}-1\right)\left(\beta_{1 . l a n d^{\dagger}}+\beta_{2 . l a n d^{\dagger}}\right)+\beta_{1 . i n c o m e}+\beta_{2 . \text { income }}}{\beta_{1 . \text { business }}+\beta_{2 . b u s i n e s s}+\beta_{1 . \text { land }}+\beta_{2 . l a n d^{\dagger}}+\beta_{1 . \text { agriculture }}+\beta_{2 . \text { agriculture }}}+1\right)^{12}-1
$$

Once again, $x \in\{4,18\}$ denotes time in months between baseline and the relevant endline, and $\beta_{1}$ and $\beta_{2}$ are the coefficients on winning the lottery and the additional effect of winning the large lottery, respectively (as specified in Equation 9). We estimate 95\% confidence intervals around the returns on investment for the small and large grant. These returns for the first endline are shown at the bottom of Table 7 . While imprecisely estimated, the mean ROI on the large grant is $28 \%$, but given the wide $95 \%$ confidence interval ranging from $-38 \%$ to $95 \%$, we also cannot rule out large positive returns.

\subsubsection{Medium Term Results}

We show the second endline results in Tables 8 (OLS) and 9 (SUR). For small grant winners, the point estimates on savings (41,000 UGX, not significant) and business investment (250,000 UGX, significant at the 10 percent level) are similar to the first endline. However, standard errors are larger and we cannot detect persistent effects 18 months after grant receipt. The effect of winning the small grant on agricultural investment falls by nearly 40\%, from 156,000 UGX at first endline (significant at the 5 percent level) to 97,000 UGX at second endline (not significant). Large grant winners, however, maintain and even increase

\footnotetext{
${ }^{23}$ For simplicity, we use a single $\phi$ constructed as the average across all 3 regions when calculating ROI.
} 
their investments relative to the risk-loving control group. In the SUR, we see that large grant winners retain substantial land holdings relative to the control (1,750,000 UGX, significant at the 10 percent level), and we also see suggestive evidence of greater business investment (457,000 UGX, significant at the 10 percent level). We continue to find no detectable effects on income (or consumption or credit) for either small or

large grant winners at second endline. However, ROIs could once again be quite high. At second endline, we estimate similar ROIs for both the small and large grant winners, about $40 \%$. While these remain imprecisely estimated, the confidence intervals, $[-0.38,0.95]$ for the large lottery winners and $[-2.29,0.71]$ for the small, cannot rule out substantial gains, particularly for the large grant winners.

\subsection{Disaggregate Results}

Given our detailed data on investment types and time use, we can delve more deeply into the nature of investments. We summarize these findings here and leave the details to the Appendix.

To understand whether business investment in particular may be associated with large returns, we separately estimate the returns to business investments alone. We find that average returns on business investments are higher than those for total investment, especially for the small grant winners, but have very large standard errors (Tables A.3 and A.4). In further examining the effect of the grant on the components of business investment, agricultural investment and consumption, we find that the small grant winners use the grant to purchase business inventory and invest in livestock in the short-run, and these impacts are not sustained over the longer term. Large grant winners also purchase inventory in the short-run, though this impact disappears by second endline, when instead large grant winners amass greater non-inventory business assets and household durables than the risk-loving control (in Tables A.5 and A.6). Finally, we show that both small and large grant winners temporarily shift labor hours towards household businesses in response to the grant, perhaps to support the sale of additional business inventory (Table A.7). By second endline, this impact on labor allocation is indistinguishable from zero (Table A.8).

In summary, we find that (i) winning the small lottery leads to initially higher business and agriculture investments that are indetectable a year later, (ii) relative to small grant winners and the risk-loving control, winning the larger lottery leads to substantially higher investment that persists over a year and a half and appears to be driven by land purchases, and (iii) income gains are not directly measured but we cannot rule out large returns to investment. The adding-up condition of the SUR suggests that small grant winners spend most of the grant on business investments, while large grant winners spend most of the grant on land.

\section{Calibrated Model Results}

We now return to our model of Section 2, but we use the results of our midline data and lottery choice experiment to calibrate a model of financially-constrained indivisible investment and savings dynamics. We then assess the model and constrained estimate results using simulated data, and we use the model to quantitatively assess the impact of financial intermediation. 


\subsection{Calibration}

Mapping the model to data for aggregate analysis requires adding important elements of persistent heterogeneity in the productivity of labor, $\bar{e}$, and capital, $\bar{z}$, and disciplining the other parameters of the model using data moments. ${ }^{24}$ Specifically, we assume $\bar{e}_{i}$ and $\bar{z}_{i}$ are (independently) lognormally distributed, so that $\log \bar{e}_{i} \sim \mathcal{N}\left(0, \nu_{e}\right)$ and $\log \bar{z}_{i} \sim \mathcal{N}\left(\mu_{z}, \nu_{e}\right)$, respectively. Here, assuming the mean of the $\log \bar{e}_{i}$ to be zero is a normalization.

Our calibration results and fit are summarized in Table 10. We start by assigning four parameters. First we set the maximum loan-to-value ratio $\theta=0$ in the benchmark. We do so for simplicity, but this broadly matches the limited access to credit that we observe. The interest rate $r$ then effectively becomes the interest on savings, which we set to zero, consistent with the fact that our empirical sample all held zero interest savings accounts. A period is a month, and we set the monthly maintenance cost of capital, $\delta$, which is analogous to depreciation in an indivisible capital model, to 0.01 . We set the constant survival probability, $p$, to $1-1 / 480$, implying an average adult life (or career) of 40 years.

We are left with eight parameters to calibrate: the discount factor, $\beta$; the parameters disciplining the capital technology, $\underline{k}$ (size of a unit of indivisible capital), $\alpha$ (the capital elasticity in production), $\mu_{z}, \nu_{z}$, and $\sigma_{z}$ (governing the $(\log )$ mean productivity, persistent dispersion, and productivity shock dispersion, respectively); and the parameters disciplining the labor income: $\nu_{e}$ and $\sigma_{e}$ (disciplining the dispersion of the persistent income difference and productivity shocks, respectively).

Our calibration strategy is to choose these parameters to match the the moments in the data that are most of interest to this study: the observed lottery choices, the distribution and dynamics of income, and the distribution of wealth. For the lotteries, we target the percentage of households who choose each of the four lottery choices. For the distributions of both income and savings, we target the mean as well as five percentiles of the distribution (10th, 25th, 50th, 75th, and 90th), a total of 11 moments given the normalization of median income to one in the model and in the data. ${ }^{25}$ Finally, for the dynamics of income, we target transitions across income terciles over the 16 months from baseline to midline. The $3 \times 3$ transition matrix constitutes nine additional moments. Together, these targets amount to 22 moments, substantially more than the eight free parameters we calibrate.

Given the parsimony of the model, we cannot match all moments, and instead minimize a weighted average of the sum of percentage squared deviations. ${ }^{26}$ Table 10 summarizes the parameter values and model fit. Despite the over-identification, the model fit is reasonably close, especially for our purposes. The model is able to match the fact that a substantial share choose the risky lottery $(0.20+0.04=0.24$ in the model vs. $0.20+0.07=0.27$ in the data). The share choosing to delay is somewhat smaller (0.04 vs. 0.07 , respectively),

\footnotetext{
${ }^{24}$ We examined alternative models with additional parameters such as non-unitary risk aversion, Epstein-Zin preferences (with separate risk aversion and intertemporal substitution parameters) and both physical and pecuniary fixed costs to adjusting capital, but these extensions do not significantly improve the fit over our parsimonious model.

${ }^{25}$ Savings includes only financial wealth and corresponds to $S$ in the model.

${ }^{26}$ The weights are equal to one, except for the lottery choice moments, which are critical in getting the indivisibility dynamics and so get a higher weight of 20 .
} 
but overall the share of those delaying is also comparable $(0.04+0.19=0.23$ vs. $0.07+0.14=0.21$, respectively $)$. The savings distributions are comparable with median levels of savings well below median monthly income (0.13 vs. 0.19 , respectively). Both distributions exhibit a leftward skew with the means exceeding the medians, and at least $25 \%$ of households in both distributions hold no positive savings. Of course, given the fact that our benchmark simulations have no credit, we cannot match the negative assets for those in the 10th percentile, but recalling Figure 2, this distinction is likely not crucial for our aggregate analysis. Although the right tail is lower in the model than in the data (e.g., 90th percentiles of 1.43 vs. 2.92), the mean is somewhat higher given the lack of debtors in the model.

We see that the income distributions are also broadly comparable. Though the mean income is somewhat higher in the model (1.97 vs. 1.73), due to somewhat higher weight in the tails, both distributions have a leftward skew with mean substantially higher than the median. Looking at the income transition matrix, both the model and data exhibit strong diagonal elements, showing a tendency to stay in one's income tercile, especially in the upper and lower terciles. Conditional on being in the lower income tercile, a household has a high chance of remaining there ( $67 \%$ vs. $63 \%$ ), which could be evidence of a (stochastic) poverty trap. In the middle tercile, the numbers are lower (43\% vs. 48\%), reflecting, in the model, the transitional saving dynamics of moving to one of the stable steady states (recall Figure 1).

Looking at the calibrated parameter values, we see that $\underline{k}=8.0$ implies that the indivisible investment is about 8 months of the median family income, or 40 times larger than the median level of liquid savings. The estimates of $\sigma_{\epsilon}=0.53$ and $\sigma_{z}=1.13$ indicate considerable uncertainty in labor and capital income. The first creates both variation and churning in the income distribution, while the latter simply creates variation. Finally, we note that the discount factor, $\beta=0.84$, is quite low, much lower than typically calibrated for macroeconomic studies. Models with financial frictions often yield very low discount factors, however, which is needed to prevent people from simply saving out of the range of financial frictions (e.g., Buera et al. (2020)). Note that in this calibration, the presence of high yield investment opportunities will generate patience among a world of impatient agents rather than impatience among the otherwise patient.

\subsection{Model Regressions}

Having shown that the parsimonious model is able to broadly mimic the non-experimental data, including the observed lottery choices, we examine the extent to which the model can provide rationale for and add insight into our key empirical finding on the impact of lottery winnings. Specifically, we ask whether, first, the model replicates the fact that winners of the large lottery make large, indivisible investments and even in excess of their winnings. Furthermore, we ask whether our use of the SUR cross-equation budget constraints can be justified through the lens of the model.

Clearly, there are other empirical findings along which the parsimonious model is limited. We note two important examples of limitations. First, with only one investment good, the indivisible good which we will interpret as land, the model cannot replicate the investment in agricultural and business assets that small 
lottery winnings yield. Second, in the data capital gains appear to be an important return to investment in land, but in the model the returns to the indivisible investment are through realized income. Realized income leads to higher levels of both savings and consumption. Hence, we focus on capital investment in the model and compare it to land investment in the data.

To do so, we generate 500 samples of individual simulations from the ergodic distribution in model. These samples are identical in size to our empirical sample, 867 agents, and we have the full series of simulated monthly data for consumption, savings, income, and capital investment, with 16 months between baseline and midline. At midline, we simulate lotteries with lottery choice proportions and lottery winning proportions matching the field experiment via construction. We then simulate 4 months between midline and first endline, and 18 months between midline and second endline to again match the empirics.

Using these simulated data, we run Monte Carlo regressions analagous to those in equation (9), with slight necessary modifications given the model. First, with only one capital good, we have only a single investment outcome (rather than agricultural investment, business investment, and land as separate outcomes). We focus on land investment as the empirical comparison, since business investment and agricultural investment are less discrete. ${ }^{27}$ Second, we have no demographic controls except age and age ${ }^{2}$, and no geographic controls. Third, in the application of the cross-equation restriction (equation 10, for our SUR regressions with cross-equation restrictions), we omit borrowing, which is zero by assumption.

Finally, in constructing our income and consumption outcomes, we distinguish between the true measure in the budget constraint (which we call "True Values"), an approach that more closely mirrors our empirics ("Empirical Proxy"), and an approach which introduces true measurement bias into the data used ("Biased Measurement"). "True Values" constructs income and consumption as sums of the full series between midline and (first) endline. "Empirical Proxy" constructs them as we do in the empirics, using the endline value multiplied by the number of months between midline and endline. ${ }^{28}$ The point of "Empirical Proxy" is that our measurement at a point in time automatically introduces some deviation from the budget constraint.

Lastly, we account for two features of the empirical data not present in the model. First, the model has only one value for capital (land) investment and so, the precision of the estimates is quite high. In the empirical data, land purchases are of varied size and also likely reflect considerable measurement error. Second, expenditures may suffer not only from classical measurement error but actual bias. To mimic this, we consider multiplicative measurement error, multiplying land realizations in the simulated data by the random variable, $X=\tilde{X} \mu_{e}$, where $\tilde{X}$ is a log-normally distributed random variable with mean of one and $\log$ variance of $\nu_{e}^{2}$. Here $\nu_{e}=1.9$ is calibrated to match the average standard error on the coefficient for winning the large lottery to our empirical standard error. The coefficient $\mu_{e}=2.2$ captures the bias in measurement and its value is calibrated to equal the average ratio of expenditures to income in the pre-

\footnotetext{
${ }^{27}$ Other work has emphasized the indivisibility or minimum scale of livestock that can lead to poverty traps, e.g., Balboni et al. (forthcoming); Barrett et al. (2019).

${ }^{28}$ For consumption, we multiply endline values times the number of months minus one and then add consumption from the month directly after the midline. The empirics combines the past week's consumption with durable purchases since midline. Since these durables are likely purchased upon receiving winnings, we choose this as the closest analog because immediate consumption after winnings is generally highest.
} 
experimental data, much of which may reflect overstatement of land values as discussed in Section 3.2. We call this alternative set of simulated data "Measurement Error".

Table 11 presents a summary of the results of these regressions on simulated data focusing on the investment outcome. The top panel presents results for the estimates of the impacts of winning the (small) lottery. In the first two columns, we see that across all estimation techniques the mean coefficients average small positive numbers, but the mean standard errors dwarf the mean coefficients. Using the Measurement Error data, standard errors on the OLS coefficient is comparable to that in the empirics $(847,510$ vs. 884,518$)$. Looking at the SUR budget constraint, we see that the mean p-value for rejecting the constraint on winning the small lottery are high, and it is rejected in roughly $5 \%$ of the samples.

The lower panel shows results for the incremental impacts of winning the large/risky lottery, which are of greater interest. The model is able to generate the surprisingly large coefficients on winning the large/risky lottery that (based on point estimates) indicate that the additional expenditures on land actually exceed the incremental grant winnings of 1,350,000 UGX. Using the True Values, the estimated coefficients average roughly 2,000,000 with very small standard errors $(11,837) .{ }^{29}$ These values are within the confidence bands of the SUR estimate in Table 7 of 1,522,877 (standard error: 424,702). Moreover, the SUR estimation for the True Values yields high average p-values and the budget constraint is rarely rejected. Using the SUR on the Empirical Proxy, the average coefficient is virtually identical. ${ }^{30}$ However, the average p-value of the SUR budget constraint is 0.16 for those winning the large lottery, and the constraint is rejected in $54 \%$ of the regressions. This combination helps alleviate concerns about our relatively low empirical p-value of 0.06 on the constraint. Finally, we turn to the Measurement Error regressions. By construction, the average OLS standard error in the estimates equals the empirical value of roughly $1,800,000$. The estimated coefficients are much larger with the biased measurement error, averaging roughly 4,100,000 in the simulations, which compares well with the roughly 4,800,000 in the empirics, especially given the large standard errors. Focusing now on the SUR estimates for the Measurement Error data, we see that applying the SUR budget constraint yields coefficients close to the true coefficient in the model of just over 2,100,000 and with a much smaller average standard error of roughly 210,000. These patterns mimic those in the actual data. Indeed, this coefficient in the empirics is statistically indistinguishable, roughly 1,500,000 with a standard error of about 400,000. The p-values on the large constraint average 0.28 , but the constraint is again rejected often (in $38 \%$ of the samples).

Together, these estimates show the usefulness of the SUR in a situation where biased measurement error can lead to unreasonably large estimates. As argued in the empirics, the SUR returns reasonable estimates (true to the actual estimates) and smaller standard errors. Moreover, the SUR yields the true value despite the fact that the budget constraint can be rejected at times.

\footnotetext{
${ }^{29}$ For all estimations and simulated data, the realized $95 \%$ confidence intervals for the distributions of the estimated coefficients closely reflect those expected by the standard errors of the coefficients.

${ }^{30}$ We omit OLS for the Empirical Proxy, since it only changes consumption.
} 


\subsection{Counterfactual Assessment of Introduction of Financial Services}

We now use the model to evaluate the impacts of introducing wide-scale financial services to the regions of study. We assess two different policies. The first is an expansion of credit services that enables households to borrow up to (a relatively modest) $25 \%$ of the value of their capital, which we model as an increase of the collateral parameter, $\theta$, from 0 to 0.25 . The second is an expansion of interest-bearing savings facilities, which we model as an increase in the interest rate, $r$, from 0 to 0.05 .

We assess these policies under two different scenarios about the supply of capital. The first is a scenario where capital is perfectly elastically supplied at a constant price, as is typically assumed in macro models of investment. In this case, only quantities will adjust to an increase in the demand for investment. Such an assumption is surely appropriate when the intervention is small relative to overall supply of capital, and so we label this "PE". The second scenario is one in which capital is in fixed supply. Such a scenario is an extreme scenario but perhaps more appropriate for the case when land is the investment good. In this case, prices will adjust to changes in the demand for capital rather than aggregate quantities, and so we label this "GE". We note, however, that both scenarios are extremes, and reality, reflecting an upward sloping supply of capital, is likely to be somewhere in between.

Table 12 presents the results for both policies under both scenarios. We focus on the impacts of these policies on aggregates: income, consumption, net savings, capital, the value (price $\times$ quantity) of capital, the price of capital, and capital income. Given our interest in poverty traps and wealth dynamics, we also report the fraction of the poor in the economy (i.e., the fraction below a threshold defined by the lowest tercile of wealth in the benchmark economy) and the probability of staying poor. We report all of the counterfactual results relative to the benchmark values (which are given in the notes of Table 12 but not otherwise of particular interest). We point out that although savings and capital are positive, consumption equals income in the steady state because capital does not depreciate and income is already net of maintenance costs. That is, steady state investment is zero in the economy whether capital is elastically or inelastically supplied.

We focus first on the credit intervention, which is quite powerful when the price of investment is fixed. Under this scenario ('Credit' and 'PE' in the table), the capital stock is $130 \%$ larger and income is $53 \%$ larger. Capital income rises slightly more due to a better allocation of capital. Net savings declines, a combination of both credit and decreased savings for self-financing reasons, but by only $9 \%$. The fraction poor declines by $32 \%$, although the chances of staying poor remain the same.

In striking contrast, in the case of credit under a fixed stock of capital, we see absolutely no impact on aggregate income, capital income, or poverty. Indeed, the policy is completely neutral even on the micro level. The change in $\theta$ is completely offset by a commensurate change in price, where $P=1 /(1-\theta)$ or 1.33 in this case. Net savings declines as households simply keep their surplus savings above available credit, i.e., $\hat{a}=a^{\prime}+\theta P k^{\prime}$, unchanged. Indeed, given our assumptions, one can easily show this neutrality result analytically. ${ }^{31}$ The key point is that the power of credit to increase output and reduce poverty is substantially

\footnotetext{
${ }^{31}$ To see this, recall that $\theta$ only impacts the household's problem through the borrowing constraint, $a^{\prime} \geq-\theta P k^{\prime}$. Define
} 
reduced in a world where the increased demand for investment manifests itself more in an increase in prices than through an increase in productive capital.

The results for the savings intervention demonstrate that when the investment price is fixed, interestbearing savings can also be a powerful financial intervention. Under a fixed price of capital, savings responds considerably to the positive return on savings, increasing by $76 \%$, a strong contrast to the impact of the credit policy. However, capital increases by $39 \%$, capital income increases by $45 \%$, and overall income rises by $22 \%$. The impact of savings on poverty is perhaps as dramatic as in the credit intervention, as the fraction poor drops by $30 \%$ and the probability of staying poor is $23 \%$ lower in the savings distribution. The "poverty trap" is therefore weakened.

When we look at the case of capital in fixed supply, although the perfect neutrality result no longer holds, the aggregate impacts are nonetheless tempered. The price of capital increases but by only $11 \%$, showing that the savings intervention doesn't increase the demand for investment quite as much as the credit program. Income rises by only $4 \%$, as does capital income. Here labor income is fixed, but interest becomes an important source of income. Savings rises by $37 \%$, and both higher savings and a positive interest rate lead to interest income. ${ }^{32}$ Hence, while the aggregate results are tempered, they are not completely neutral. Moreover, because it affects the accumulation of savings, the program still has important impacts on poverty. The fraction poor drops by $23 \%$ even under a fixed supply of land, and poverty is again much less persistent with the probability of staying poor dropping by $24 \%$.

In summary, the aggregate simulation results underscore that the power of financial interventions, even in a world with indivisible investments, hinge critically on the elasticity of the supply of capital. General equilibrium forces can undermine positive aggregate impacts measured in partial equilibrium experiments.

\section{Evidence of GE Effects for Land}

The model in Section 2 indicated that risk-loving behavior can be linked to large, indivisible investments, while the the previous section showed that if the investment good is not elastically supplied, the aggregate impacts of financial services can be limited through general equilibrium forces. Given that the empirics in Section 4 demonstrated that winners of a risky lottery have a large propensity to invest winnings by purchasing land, and that land price appreciation (2 percent per month) is important (Section 3.2), a natural question is whether general equilibrium forces are important for land. That is, does demand for land

$\hat{a}=a^{\prime}+\theta P k^{\prime}$ as surplus savings above the lower bound. Then combining the recursive constraints (2) and (4) to eliminate $l$, substituting in for $\hat{a}$, and simplifying using $r=0$ yields the following constraints:

$$
c+\hat{a}+P(1-\theta)\left(k^{\prime}-k\right)=e+\hat{a}-\theta P k+z k^{a} l p h a-\delta k
$$

and

$$
\hat{a} \geq 0 \text {. }
$$

It is clear that any change from $\theta$ to $\theta^{\prime}$ is simply offset by a general equilibrium change in the price of capital from $P$ to $P^{\prime}=P(1-\theta) /\left(1-\theta^{\prime}\right)$, and no household's problem is affected, except that while $\hat{a}$ remains constant, $a^{\prime}$ adjusts dramatically (by $62 \%$ ) to offset the change in available credit according to the equation that holds by definition, $\hat{a}=a^{\prime}+\theta P k^{\prime}$. The clarity of this analytical neutrality result is further justification for the $r=0$ assumption.

${ }^{32}$ Our neutrality result for credit hinged on zero interest loans. In the case where loans are positive interest there would be distributional consequences as well. 
investment increase the prices of land?

Given the high propensity to purchase land out of risky lottery winnings, our randomized experiment generated exogenous variation in the demand for land. We therefore test the impact of the local grant winnings on land values by estimating the impact of more grant money being awarded within close proximity to a participant household, using 0.5 and 1 mile radii around the household as measures of proximity. That is, we run the following two-stage regression:

$$
\begin{aligned}
& \Delta \text { LocalLandValue }_{i d}=\beta_{0}+\beta_{1} \text { WinningsWithinRadius }_{i}+\gamma X_{i}+\lambda_{d}+\varepsilon_{i d} \\
& \text { HouseholdLandValue }_{i d}=\beta_{0}+\beta_{1} \Delta \text { LocalLand Value }_{i}+\gamma X_{i}+\lambda_{d}+\varepsilon_{i d}
\end{aligned}
$$

Where $X_{i}$ controls for the (sample) number of households within the radius of interest ( 0.5 miles or 1 mile), the number of households choosing the large lottery within the radius, the household's own individual lottery winnings, whether the household chose the large lottery, the household's baseline land value, the household's monthly income, and the same set of demographic controls included in our main estimating equation (Equation 9). We also include $\lambda_{d}$, district fixed effects, as in our main estimating equation. In this specification, the independent variation in winnings is the result of the realization of random draws within the area. The winnings within a given radius vary at the household-level, where we sum the total winnings of all surrounding households within the given radius. We cluster standard errors by the 141 geographic "neighborhoods" used in our census survey (with an average of 6 households per geographic unit).

Table 13 presents the impact of local winnings on local land values. We find that each additional shilling of grant money awarded within $\frac{1}{2}$ mile increases local land values at the first endline by 5.4 shillings. The effect is even larger in a 1 mile radius - each shilling of grant winnings increases values by 11 shillings. This suggests that a large grant invested in land will lead to an increase in land values of 19.25 million in the region. ${ }^{33}$ While the first stage is a bit weak in the 0.5 mile radius specification with an F-statistic of 6.7 , the F-statistic for the one mile specification is 20 and 13 for the first and second endlines, respectively.

In the second stage (Table 14), we find that a one shilling increase in neighboring land values leads to a 0.042 shilling increase in the household's land values in the first endline (using the 1 mi radius specification). The point estimate is slightly smaller at 0.03 and the standard errors are slightly larger for the second endline, so the second endline result is not statistically significant. The impact of an additional large grant invested in land within one mile would therefore be 808,000 shillings at the first endline and 654,500 shillings at the second endline, or an approximately $3.1 \%$ increase in land value.

Hence, we have direct evidence of price increases resulting from the demand for land, indicating that land is not perfectly elastically supplied even in the underbanked, peri- and semi-urban small cities that we study. In the context of our model, this limits the impacts that financial services can have in promoting development

\footnotetext{
${ }^{33}$ The effects are large, but if one unit of land is sold above the status quo price, the values of all land may increase correspondingly. Indeed, this indirect impact is precisely our interest. Note also that the impact may also include any increase in local growth from people investing in their businesses.
} 
and the escape from poverty. Moreover, the emphasis on land as an investment good disproportionately favors savings services relative to credit services toward these ends, since credit had no impact when the investment capital was in fixed supply.

\section{Conclusions}

We have examined the importance of high-yield, indivisible investments in peri- and semi-urban Uganda, where financial services are limited. Empirically, we have shown a risk-loving demand for large-stakes lotteries, especially among those who have self-financing motives for savings and investment motives for demanding credit. Winners of these risky lotteries invest disproportionately in land, but we do not find large income gains to receiving funds among this group, even after 18 months. While profitability is not obvious, we do observe increasing land prices that may reflect sizable capital gains. Moreover, we observe that exogenous increases in demand from our cash grants cause increases in land prices. The risk-loving behavior we observe is consistent with theories of high-yield indivisible investments, which, in principle, can lead to sizable gains to financial intermediation. However, our theory demonstrates that when these investments are inelastically supplied, the impacts on aggregate outcomes and poverty can be substantially less, especially the impact of credit services. Our observations of the importance of land and land price increases in response to investment demand are consistent with investments being somewhat inelastic. Together, despite the riskloving behavior and demand for indivisible investments consistent with poverty traps, the lack of clear income gains, as well as the fact that it is used to fund land, indicate that these indivisibilities may be less important

for aggregate development. From a policy perspective, the results indicate that relatively more importance should be placed on interest-bearing savings, perhaps along the lines of Greaney et al. (2016).

We believe the substance of our results are important, but we also make methodological strides. Perhaps foremost, the application of the budget constraint in an SUR estimation is a novel application of simple theory that is potentially useful in other contexts for increasing the precision of estimates and yielding more easily interpretable results from costly experiments.

Substantively, the findings about land elicit questions of their own for future research. Poverty trap dynamics have been observed for smaller investments such as livestock, which are profitable and more elastically supplied (e.g., Balboni et al. (forthcoming)), but the importance of land merits more consideration. The development literature has focused on the interaction of finance, land titling, and investment, and also the link between land plots, overall farm size, and misallocation (e.g, Foster and Rosenzweig (forthcoming); Gollin and Udry (2021)), but the issues we raise are unique. How common are land-driven poverty traps and how important is land titling policy to the indivisibilities we uncover? Finally, our results indicate that, even outside of major urban areas, land may be an important investment for the poor. The lack of clear evidence on returns to land is an important limitation of the findings, but also inspires further research on whether land is simply valued in preferences or perhaps plays an important insurance role. More research on these aspects of land markets is therefore encouraged. 


\section{References}

Balboni, C., O. Bandiera, R. Burgess, M. Ghatak, and A. Heil (forthcoming): "Why do people stay poor?" Quarterly Journal of Economics.

Banerjee, A., E. Breza, E. Duflo, and C. Kinnan (2019): "Can microfinance unlock a poverty trap for some entrepreneurs?" Tech. rep., National Bureau of Economic Research.

Banerjee, A. V. and A. F. Newman (1993): "Occupational choice and the process of development," Journal of Political Economy, 101, 274-298.

Barrett, C. B., M. R. Carter, and J.-P. Jean Paul Chavas (2019): The Economics of Poverty Traps, Cambridge, MA: National Bureau of Economic Research, Inc.

Bergquist, L., B. Faber, T. Fally, M. Hoelzlein, E. Miguel, and A. Rodriguez-Clare (2019):

"Scaling Agricultural Policy Interventions: Theory and Evidence from Uganda," Unpublished manuscript, University of California at berkeley.

Blattman, C., N. Fiala, and S. Martinez (2014): "Generating skilled self-employment in developing countries: Experimental evidence from Uganda," The Quarterly Journal of Economics, 129, 697-752.

Blattman, C., E. P. Green, J. Jamison, M. C. Lehmann, and J. Annan (2016): "The returns to microenterprise support among the ultrapoor: A field experiment in postwar Uganda," American Economic Journal: Applied Economics, 8, 35-64.

Bruhn, M. And D. McKenzie (2009): "In Pursuit of Balance: Randomization in Practice in Development Field Experiments," American Economic Journal: Applied Economics, 1, 200-232.

Buera, F. J. (2009): "A dynamic model of entrepreneurship with borrowing constraints: theory and evidence," Annals of Finance, 5, 443-464.

Buera, F. J., J. P. Kaboski, And Y. Shin (2014): "Macro-perspective on asset grants programs: Occupational and wealth mobility," American Economic Review, 104, 159-64.

(2015): "Entrepreneurship and financial frictions: A macrodevelopment perspective," Annual Reviews of Economics, 7, 409-436.

_ (2020): "The Macroeconomics of Microfinance," The Review of Economic Studies, 88, 126-161.

Buera, F. J. And Y. Shin (2013): "Financial frictions and the persistence of history: A quantitative exploration," Journal of Political Economy, 121, 221-272.

Carter, M. R. And T. J. Lybbert (2012): "Consumption versus asset smoothing: testing the implications of poverty trap theory in Burkina Faso," Journal of Development Economics, 99, 255-264. 
De Mel, S., D. McKenzie, And C. Woodruff (2008): "Returns to capital in microenterprises: evidence from a field experiment," The Quarterly Journal of Economics, 123, 1329-1372.

(2014): "Business training and female enterprise start-up, growth, and dynamics: Experimental evidence from Sri Lanka," Journal of Development Economics, 106, 199-210.

Donovan, K. (2020): "The Equilibrium Impact of Agricultural Risk on Intermediate Inputs and Aggregate Productivity," The Review of Economic Studies.

Egger, D., J. Haushofer, E. Miguel, P. Niehaus, and M. W. Walker (2019): "General equilibrium effects of cash transfers: experimental evidence from Kenya," Tech. rep., National Bureau of Economic Research.

Foster, A. D. And M. R. Rosenzweig (forthcoming): "Are There Too Many Farms in the World? Labor Market Transaction Costs, Machine Capacities, and Optimal Farm Size," Journal of Political Economy.

Galor, O. And J. Zeira (1993): "Income distribution and macroeconomics," The Review of Economic Studies, 60, 35-52.

Gochberg, W. (2021): "The social costs of titling land: Evidence from Uganda," World Development, 142, 105376.

Gollin, D. AND C. UdRY (2021): "Heterogeneity, Measurement Error, and Misallocation: Evidence from African Agriculture," Journal of Political Economy, 129, 1-80.

Greaney, B. P., J. P. Kaboski, and E. Van Leemput (2016): "Can self-help groups really be âselfhelpâ?" The Review of Economic Studies, 83, 1614-1644.

Haushofer, J. And J. Shapiro (2016): "The short-term impact of unconditional cash transfers to the poor: experimental evidence from Kenya," The Quarterly Journal of Economics, 131, 1973-2042.

- (2018): "The long-term impact of unconditional cash transfers: experimental evidence from Kenya," Tech. rep., Busara Center for Behavioral Economics, Nairobi, Kenya.

Kaboski, J. P. And R. M. Townsend (2011): "A structural evaluation of a large-scale quasi-experimental microfinance initiative," Econometrica, 79, 1357-1406.

Kaplan, G. and G. L. Violante (2014): "A Model of the Consumption Response to Fiscal Stimulus Payments," Econometrica, 82, 1199-1239.

Kaplan, G., G. L. Violante, and J. Weidner (2014): "The Wealthy Hand-to-Mouth," Brookings Papers on Economic Activity, 45, 77-153.

Lagakos, D., M. Mobarak, and M. Waugh (2018): "The Welfare Effects of Encouraging Rural-Urban Migration," Working Papers 2018-002, Human Capital and Economic Opportunity Working Group. 
Lybbert, T. J. And C. B. Barrett (2011): "Risk-Taking Behavior in the Presence of Nonconvex Asset Dynamics," Economic Inquiry, 49, 982-988.

Lybbert, T. J., C. B. Barrett, S. Desta, And D. L. Coppock (2004): "Stochastic Wealth Dynamics and Risk Management among a Poor Population," The Economic Journal, 114, 750-777.

McKenzie, D. J. And C. Woodruff (2006): "Do Entry Costs Provide an Empirical Basis for Poverty Traps? Evidence from Mexican Microenterprises," Economic Development and Cultural Change, 55, 3-42.

Midrigan, V. AND D. Y. XU (2014): "Finance and misallocation: Evidence from plant-level data," American Economic Review, 104, 422-58.

PiketTy, T. (1997): "The dynamics of the wealth distribution and the interest rate with credit rationing," The Review of Economic Studies, 64, 173-189.

Tibshirani, R. (1996): "Regression shrinkage and selection via the lasso," Journal of the Royal Statistical Society: Series B (Methodological), 58, 267-288.

\section{Figures}

Figure 1: Asset-Dependent Behavior and Poverty Traps
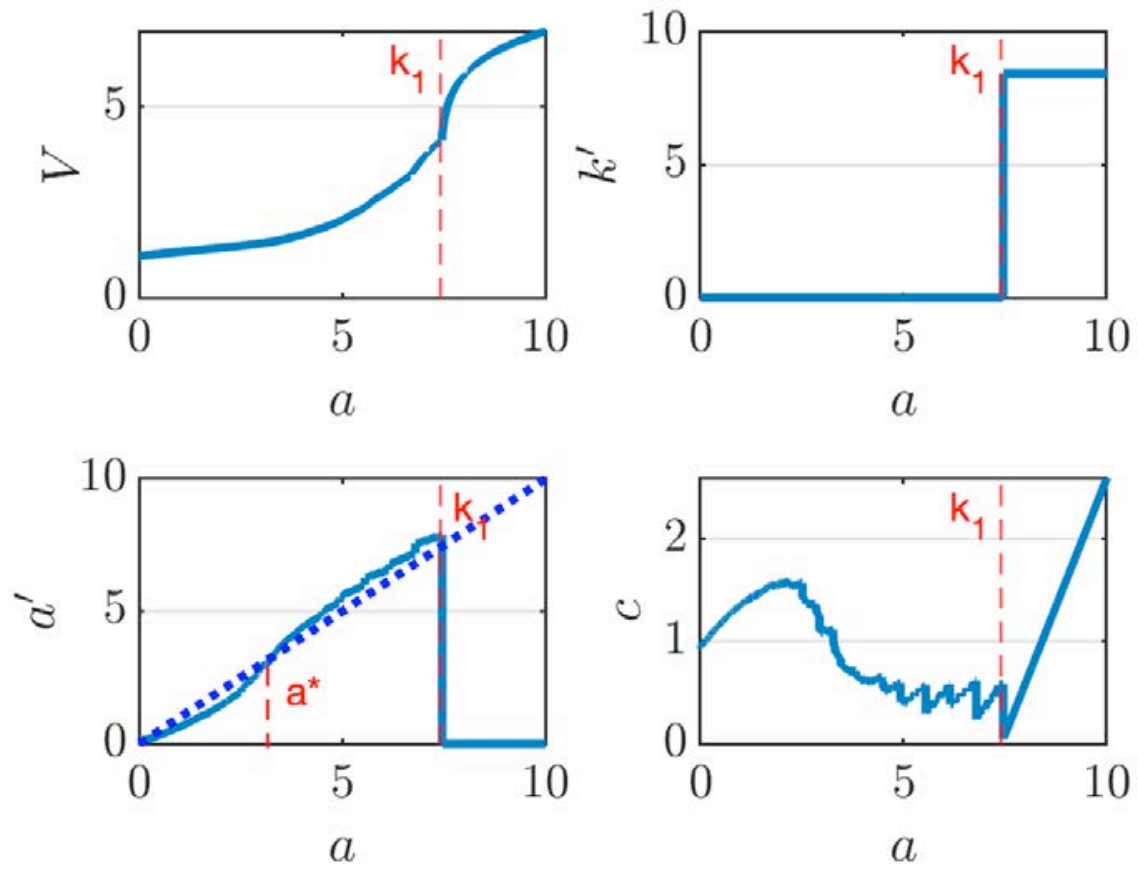
Figure 2: Asset-Dependence of Lottery Choice

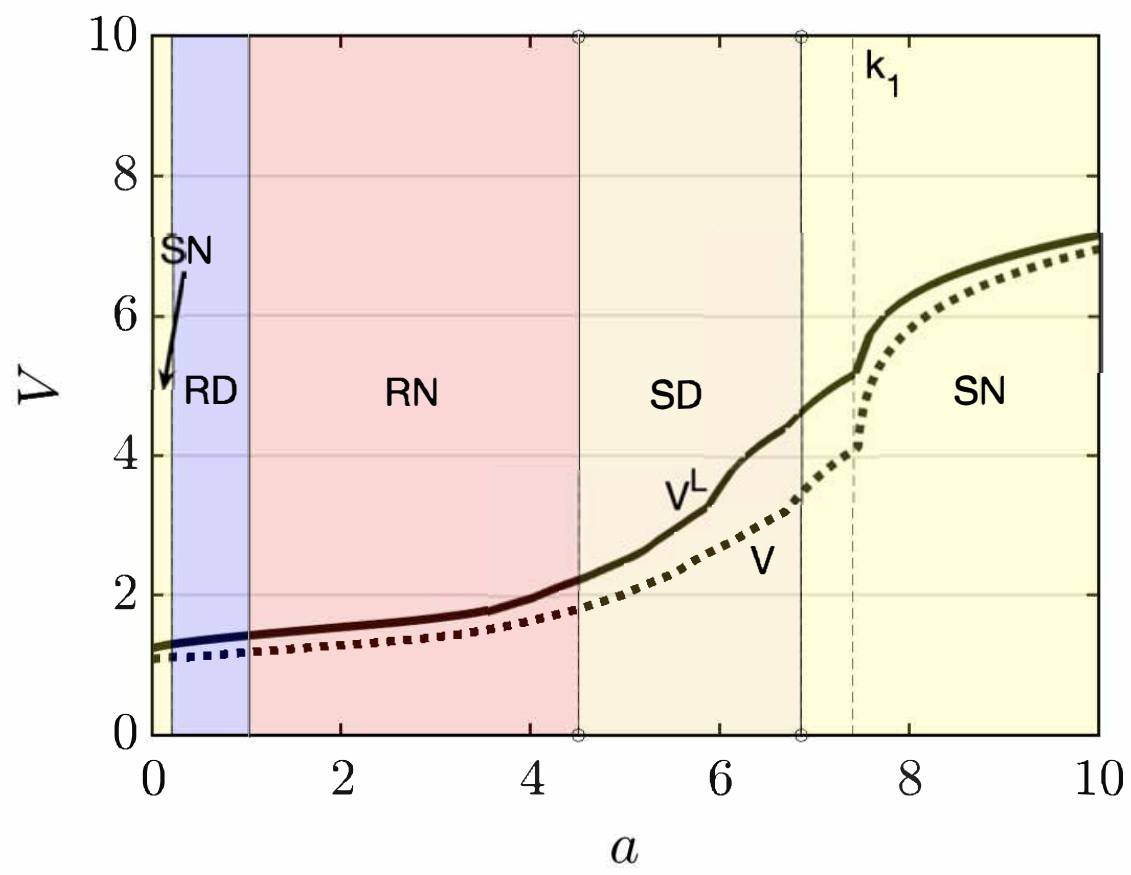

\section{Tables}

Table 1: Lottery choices

\begin{tabular}{lrr|r}
\hline \hline & High-risk & Low-risk & Total \\
\hline Patient & 78 & 144 & 222 \\
& $(7 \%)$ & $(14 \%)$ & $(21 \%)$ \\
Impatient & 204 & 622 & 826 \\
& $(20 \%)$ & $(59 \%)$ & $(79 \%)$ \\
\hline Total & 282 & 766 & 1,048 \\
& $(27 \%)$ & $(73 \%)$ & $(100 \%)$ \\
\hline \hline
\end{tabular}

Table 2: Lottery winners

\begin{tabular}{lrr|r}
\hline \hline & High-risk & Low-risk & Total \\
\hline Patient & 16 of $78=21 \%$ & 71 of $144=49 \%$ & 87 of $222=39 \%$ \\
Impatient & 62 of $204=30 \%$ & 303 of $622=49 \%$ & 365 of $826=44 \%$ \\
\hline Total & 78 of $282=28 \%$ & 374 of $766=49 \%$ & 452 of $1,048=43 \%$ \\
\hline \hline
\end{tabular}


Table 3: Balance between low lottery winners and the low-risk control, endline sample

\begin{tabular}{|c|c|c|c|c|c|c|}
\hline & won low lottery & $\mathrm{N}$ & low-risk control & $\mathrm{N}$ & diff & p-value \\
\hline mthly income $_{m}$ & 362,174 & 326 & 385,259 & 309 & $-23,085$ & 0.43 \\
\hline mthly bus income $_{m}$ & 114,237 & 326 & 127,270 & 309 & $-13,033$ & 0.41 \\
\hline mthly crop income $_{\mathrm{m}}$ & 72,120 & 326 & 74,091 & 309 & $-1,971$ & 0.79 \\
\hline wkly cons ${ }_{m}$ & 40,282 & 326 & 39,478 & 309 & 804 & 0.72 \\
\hline savings $_{\mathrm{m}}$ & 289,485 & 326 & 268,359 & 309 & 21,125 & 0.51 \\
\hline $\operatorname{land}_{\mathrm{b}}$ & $9,914,264$ & 326 & $10,091,586$ & 309 & $-177,322$ & 0.87 \\
\hline has formal savings $\mathrm{s}_{\mathrm{m}}(0 / 1)$ & .11 & 326 & .15 & 309 & -.035 & 0.18 \\
\hline operated business $_{m}(0 / 1)$ & .53 & 326 & .55 & 309 & -.023 & 0.57 \\
\hline farmer $_{m}(0 / 1)$ & .75 & 326 & .77 & 309 & -.022 & 0.53 \\
\hline work hours per week $\mathrm{m}_{\mathrm{m}}$ & 77 & 326 & 78 & 309 & -.94 & 0.59 \\
\hline experienced bad event $_{m}(0 / 1)$ & .64 & 326 & .68 & 309 & -.035 & 0.35 \\
\hline acquired loans since baseline $_{\mathrm{m}}(0 / 1)$ & .32 & 326 & .33 & 309 & -.008 & 0.83 \\
\hline num adult females $b$ & 1.1 & 326 & 1.2 & 309 & $-.08^{*}$ & 0.07 \\
\hline num adult males $_{\mathrm{b}}$ & 1.4 & 326 & 1.4 & 309 & .038 & 0.65 \\
\hline num children $_{\mathrm{b}}$ & 2.5 & 326 & 2.4 & 309 & .077 & 0.56 \\
\hline education beyond primary school $(0 / 1)$ & .28 & 326 & .28 & 309 & -.0087 & 0.81 \\
\hline female $(0 / 1)$ & .47 & 326 & .52 & 309 & -.052 & 0.19 \\
\hline household head $(0 / 1)$ & .61 & 326 & .6 & 309 & .0054 & 0.89 \\
\hline respondent age & 35 & 326 & 37 & 309 & -1.1 & 0.21 \\
\hline Observations & 635 & & & & & \\
\hline
\end{tabular}

All quantities in UGX; Outliers top/bottom coded to 95 th $/ 5$ th percentile. ${ }^{*} p<0.1,{ }^{* *} p<.05,{ }^{* * *} p<0.01$

Table 4: Balance between high lottery winners and the high-risk control, endline sample

\begin{tabular}{lcccccc}
\hline \hline & & & & & \\
& won high lottery & $\mathrm{N}$ & high-risk control & $\mathrm{N}$ & diff & p-value \\
\hline mthly income $_{\mathrm{m}}$ & 426,999 & 73 & 378,105 & 159 & 48,894 & 0.37 \\
mthly bus income $_{\mathrm{m}}$ & 140,514 & 73 & 112,689 & 159 & 27,825 & 0.29 \\
mthly crop income $_{\mathrm{m}}$ & 95,860 & 73 & 96,020 & 159 & -160 & 0.99 \\
wkly cons $_{\mathrm{m}}$ & 46,802 & 73 & 43,875 & 159 & 2,927 & 0.49 \\
savings $_{\mathrm{m}}$ & 354,014 & 73 & 281,918 & 159 & 72,095 & 0.19 \\
land $_{\mathrm{b}}$ & $15,770,274$ & 73 & $12,821,698$ & 159 & $2,948,576$ & 0.19 \\
has formal savings $_{\mathrm{m}}(0 / 1)$ & .055 & 73 & .094 & 159 & -.04 & 0.31 \\
operated business $_{\mathrm{m}}(0 / 1)$ & .62 & 73 & .61 & 159 & .0064 & 0.93 \\
farmer $_{\mathrm{m}}(0 / 1)$ & .74 & 73 & .71 & 159 & .029 & 0.65 \\
work hours per week $_{\mathrm{m}}$ & 77 & 73 & 77 & 159 & -.62 & 0.86 \\
experienced bad event $_{\mathrm{m}}(0 / 1)$ & .63 & 73 & .62 & 159 & .0075 & 0.91 \\
acquired loans since baseline $_{\mathrm{m}}(0 / 1)$ & .23 & 73 & .33 & 159 & -.094 & 0.15 \\
num adult females & 1.2 & 73 & 1.1 & 159 & .057 & 0.51 \\
num adult males & 1.6 & 73 & 1.4 & 159 & .2 & 0.24 \\
num children & 2.6 & 73 & 2.9 & 159 & -.24 & 0.36 \\
education beyond primary school $(0 / 1)$ & .3 & 73 & .23 & 159 & .069 & 0.27 \\
female $(0 / 1)$ & .38 & 73 & .43 & 159 & -.05 & 0.47 \\
household head $(0 / 1)$ & .73 & 73 & .63 & 159 & .097 & 0.15 \\
respondent age & 38 & 73 & 37 & 159 & .73 & 0.65 \\
\hline Observations & 232 & & & & & \\
\hline \hline
\end{tabular}

All quantities in UGX; Outliers top/bottom coded to 95 th $/ 5$ th percentile. ${ }^{*} p<0.1,{ }^{* *} p<.05,{ }^{* * *} p<0.01$ 
Table 5: Significant differences between those selecting the high-risk v. low-risk lottery

\begin{tabular}{|c|c|c|c|c|c|c|}
\hline & high-risk & 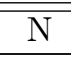 & low-risk & $\overline{\mathrm{N}}$ & 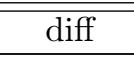 & $\overline{\mathrm{p} \text {-value }}$ \\
\hline \multicolumn{7}{|l|}{ Income and consumption } \\
\hline$\Delta$ ln mthly income $\mathrm{m}_{\mathrm{b}}$ & .71 & 282 & 1.2 & 766 & -.46 & 0.02 \\
\hline mthly crop income ${ }_{m}^{*}$ & 100,060 & 282 & 71,240 & 766 & 28,820 & 0.00 \\
\hline crop income/total income ${ }_{m}$ & .3 & 282 & .26 & 766 & .047 & 0.01 \\
\hline mthly crop income/adult equiv ${ }_{m}$ & 30,418 & 282 & 23,044 & 766 & 7,374 & 0.00 \\
\hline ln mthly crop income ${ }_{m}$ & 9.7 & 282 & 9.1 & 766 & .62 & 0.03 \\
\hline wkly consm & 44,553 & 282 & 39,428 & 766 & 5,124 & 0.01 \\
\hline ln wkly $\operatorname{cons}_{\mathrm{m}}$ & 10 & 282 & 10 & 766 & .15 & 0.02 \\
\hline$\Delta \ln$ wkly cons $\mathrm{m}_{\mathrm{b}}$ & .38 & 282 & .23 & 766 & .15 & 0.02 \\
\hline \multicolumn{7}{|l|}{ Wealth } \\
\hline bus assets $_{\mathrm{m}}$ & 827,879 & 282 & 577,060 & 766 & 250,820 & 0.01 \\
\hline bus assets/wealth $\mathrm{m}_{\mathrm{m}}$ & .29 & 282 & .24 & 766 & 054 & 0.04 \\
\hline bus assets/adult equiv ${ }_{m}$ & 297,007 & 282 & 218,388 & 766 & 78,619 & 0.06 \\
\hline ln bus assets ${ }_{m}$ & 5.2 & 282 & 4.2 & 766 & .98 & 0.03 \\
\hline savings $_{\mathrm{m}}$ & 322,755 & 282 & 275,849 & 766 & 46,907 & 0.10 \\
\hline$\Delta$ ln savings $\mathrm{s}_{\mathrm{m}-\mathrm{b}}$ & 2 & 282 & 1.2 & 766 & .8 & 0.05 \\
\hline wealth $(\mathrm{sav}+\text { bus assets })_{\mathrm{m}}$ & $1,248,507$ & 282 & 919,376 & 766 & 329,132 & 0.01 \\
\hline wealth (savgs + bus assets)/adult equiv ${ }_{m}$ & 432,560 & 282 & 337,533 & 766 & 95,027 & 0.06 \\
\hline ln wealth (savgs + bus assets) ${ }_{\mathrm{m}}$ & 11 & 282 & 11 & 766 & .62 & 0.06 \\
\hline$\Delta \ln$ wealth $(\text { savgs }+ \text { bus assets })_{\mathrm{m}-\mathrm{b}}$ & 2.2 & 282 & 1.4 & 766 & .78 & 0.03 \\
\hline net wealth $(\mathrm{sav}+\text { bus assets }- \text { cred })_{\mathrm{m}}$ & $1,073,643$ & 282 & 743,837 & 766 & 329,806 & 0.01 \\
\hline net wealth (savgs + bus assets - cred)/adult equiv ${ }_{m}$ & 378,620 & 282 & 277,381 & 766 & 101,240 & 0.05 \\
\hline ln net wealth $(\text { savgs }+ \text { bus assets }- \text { cred })_{\mathrm{m}}$ & 9.9 & 282 & 8.9 & 766 & .98 & 0.02 \\
\hline$\Delta \ln$ net wealth $(\text { savgs }+ \text { bus assets }- \text { cred })_{\mathrm{m}-\mathrm{b}}$ & 2.8 & 282 & 1.3 & 766 & 1.6 & 0.00 \\
\hline \multicolumn{7}{|l|}{ Desire to invest } \\
\hline wants credit to increase income $b(0 / 1)$ & .84 & 282 & .78 & 766 & 061 & 0.03 \\
\hline would invest $>\$ 100_{\mathrm{b}}(0 / 1)$ & .95 & 282 & .91 & 766 & 038 & 0.04 \\
\hline would use credit for bus investment ${ }_{\mathrm{b}}(0 / 1)^{*}$ & .67 & 282 & .6 & 766 & .071 & 0.04 \\
\hline \multicolumn{7}{|l|}{ Demographics } \\
\hline female $(0 / 1)$ & .42 & 282 & .5 & 766 & -.085 & 0.01 \\
\hline respondent age & 37 & 282 & 35 & 766 & 2.2 & 0.01 \\
\hline HH head $(0 / 1)$ & .66 & 282 & .6 & 766 & .056 & 0.10 \\
\hline num people in $\mathrm{HH}_{\mathrm{b}}$ * & 5.5 & 282 & 5 & 766 & .48 & 0.00 \\
\hline num adult males $b$ & 1.5 & 282 & 1.4 & 766 & .14 & 0.07 \\
\hline num children ${ }_{b}$ & 2.8 & 282 & 2.5 & 766 & .35 & 0.00 \\
\hline
\end{tabular}

*Denotes a significant predictor that was also selected by LASSO in a specification with 285 covariates. 
Table 6: Grant effects on components of the household budget constraint - First endline

\begin{tabular}{|c|c|c|c|c|c|c|c|}
\hline & $\begin{array}{c}\text { (1) } \\
\mathrm{C}\end{array}$ & $\begin{array}{c}(2) \\
\mathrm{S}\end{array}$ & $\begin{array}{c}3) \\
\text { I1-bus }\end{array}$ & $\begin{array}{c}(4) \\
\text { I2-land }^{\dagger}\end{array}$ & $\begin{array}{c}(5) \\
\text { I3-ag }\end{array}$ & $\begin{array}{l}\text { (6) } \\
Y\end{array}$ & $\begin{array}{l}\text { (7) } \\
\mathrm{B}\end{array}$ \\
\hline won lottery $(0 / 1)$ & $\begin{array}{c}75,568 \\
(144,697)\end{array}$ & $\begin{array}{l}45,630^{*} \\
(26,508)\end{array}$ & $\begin{array}{l}237,163^{* *} \\
(115,551)\end{array}$ & $\begin{array}{l}-769,504 \\
(884,518)\end{array}$ & $\begin{array}{c}156,496^{* *} \\
(69,896)\end{array}$ & $\begin{array}{c}-14,874 \\
(20,473)\end{array}$ & $\begin{array}{c}-4,296 \\
(17,944)\end{array}$ \\
\hline won large lottery $(0 / 1)$ & $\begin{array}{c}-74,058 \\
(297,356)\end{array}$ & $\begin{array}{c}85,730 \\
(54,507)\end{array}$ & $\begin{array}{c}259,389 \\
(237,555)\end{array}$ & $\begin{array}{c}4,791,936^{* * *} \\
(1,819,589)\end{array}$ & $\begin{array}{c}43,310 \\
(143,575)\end{array}$ & $\begin{array}{c}31,238 \\
(41,997)\end{array}$ & $\begin{array}{l}-15,153 \\
(36,874)\end{array}$ \\
\hline risk loving $(0 / 1)$ & $\begin{array}{c}158,426 \\
(179,372)\end{array}$ & $\begin{array}{c}12,633 \\
(32,787)\end{array}$ & $\begin{array}{c}49,999 \\
(144,020)\end{array}$ & $\begin{array}{c}-1,817,732^{*} \\
(1,097,508)\end{array}$ & $\begin{array}{c}-5,429 \\
(87,274)\end{array}$ & $\begin{array}{c}-3,691 \\
(25,277)\end{array}$ & $\begin{array}{c}2,934 \\
(22,253)\end{array}$ \\
\hline district fe's & Yes & Yes & Yes & Yes & Yes & Yes & Yes \\
\hline demographic controls & Yes & Yes & Yes & Yes & Yes & Yes & Yes \\
\hline$\beta_{1}+\beta_{2}$ & 1,510 & 131,360 & 496,551 & $4,022,432$ & 199,806 & 16,364 & $-19,449$ \\
\hline P-value: $\beta_{1}+\beta_{2}=0$ & 1 & .0058 & .017 & .011 & .11 & .66 & .55 \\
\hline Control mean if risk loving $=0$ & $2,569,200$ & 259,468 & 916,786 & $14,513,024$ & 516,504 & 327,279 & 77,807 \\
\hline
\end{tabular}

Standard errors in parentheses

C: home dur \& cons; S: savings; I1: bus assets; I2: land val w cap gains; I3: ag assets \& livestk; Y: mthly income; B: net credit

Land $^{\dagger}$ refers to capital gains-adjusted land values, as in Equation 6

All quantities in UGX; Outliers top/bottom coded to 95th/5th percentile

Controls include: pre-treatment levels of outcome, income, patience, gender, hh head, age, age ${ }^{2}$, num ad females, num ad males, num children

${ }^{*} p<0.1,{ }^{* *} p<.05,{ }^{* * *} p<0.01$ 
Table 7: SUR with household budget constraint - First endline

\begin{tabular}{|c|c|c|c|c|c|c|c|}
\hline & $\mathrm{C}$ & $\overline{\mathrm{S}}$ & I1-bus & I2-land $^{\dagger}$ & I3-ag & $\bar{Y}$ & $\mathrm{~B}$ \\
\hline won lottery $(0 / 1)$ & $\begin{array}{c}105,155 \\
(133,804)\end{array}$ & $\begin{array}{c}50,114^{*} \\
(25,865)\end{array}$ & $\begin{array}{l}257,045^{* *} \\
(112,131)\end{array}$ & $\begin{array}{l}-284,785 \\
(206,677)\end{array}$ & $\begin{array}{c}170,180^{* *} \\
(66,798)\end{array}$ & $\begin{array}{l}-11,788 \\
(23,038)\end{array}$ & $\begin{array}{c}-5,137 \\
(17,919)\end{array}$ \\
\hline won large lottery $(0 / 1)$ & $\begin{array}{l}-275,379 \\
(275,002)\end{array}$ & $\begin{array}{c}64,521 \\
(53,185)\end{array}$ & $\begin{array}{c}162,817 \\
(230,522)\end{array}$ & $\begin{array}{c}1,522,877^{* * *} \\
(424,702)\end{array}$ & $\begin{array}{c}-32,801 \\
(137,224)\end{array}$ & $\begin{array}{c}25,275 \\
(47,264)\end{array}$ & $\begin{array}{c}-9,063 \\
(36,824)\end{array}$ \\
\hline risk loving $(0 / 1)$ & $\begin{array}{c}230,511 \\
(173,240)\end{array}$ & $\begin{array}{c}20,277 \\
(32,400)\end{array}$ & $\begin{array}{c}101,062 \\
(141,451)\end{array}$ & $\begin{array}{l}-605,119 \\
(873,014)\end{array}$ & $\begin{array}{c}33,899 \\
(85,300)\end{array}$ & $\begin{array}{c}-801 \\
(28,536)\end{array}$ & $\begin{array}{c}866 \\
(22,272)\end{array}$ \\
\hline district fe's & Yes & Yes & Yes & Yes & Yes & Yes & Yes \\
\hline demographic controls & Yes & Yes & Yes & Yes & Yes & Yes & Yes \\
\hline $\begin{array}{l}\text { Within-equation tests: } \\
\beta_{1}+\beta_{2} \\
\text { P-value: } \beta_{1}+\beta_{2}=0 \\
\text { Cross-equation tests: }\end{array}$ & $\begin{array}{c}-170,223 \\
.48\end{array}$ & $\begin{array}{c}114,634 \\
.013\end{array}$ & $\begin{array}{c}419,862 \\
.037\end{array}$ & $\begin{array}{c}1,238,093 \\
.0008\end{array}$ & $\begin{array}{c}137,380 \\
.25\end{array}$ & $\begin{array}{c}13,486 \\
.74\end{array}$ & $\begin{array}{c}-14,200 \\
.66\end{array}$ \\
\hline $\begin{array}{l}\text { Small grant } \\
\text { Large grant }\end{array}$ & $\begin{array}{l}\text { P-value: } \\
\text { P-value: }\end{array}$ & $\begin{array}{l}\text { Constraint } \\
\text { Constraint }\end{array}$ & $\begin{array}{l}.57 \\
.06\end{array}$ & $\begin{array}{l}95 \% \text { CI: } \\
95 \% \text { CI: }\end{array}$ & $\begin{array}{l}\mathrm{ROI} \\
\mathrm{ROI}\end{array}$ & 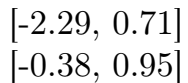 & $\begin{array}{c}\text { Mean: }-.79 \\
\text { Mean: } .28\end{array}$ \\
\hline Control mean if risk loving $=0$ & $2,569,200$ & 259,468 & 916,786 & $14,513,024$ & 516,504 & 327,279 & 77,807 \\
\hline Control mean if risk loving $=1$ & $2,864,632$ & 271,428 & $1,208,440$ & $16,118,755$ & 729,386 & 321,475 & 85,377 \\
\hline $\mathrm{R}^{2}$ & .32 & .48 & .53 & .69 & .32 & .43 & .21 \\
\hline Observations & 867 & 867 & 867 & 867 & 867 & 867 & 867 \\
\hline
\end{tabular}

Standard errors in parentheses

C: home dur \& cons; S: savings; I1: bus assets; I2: land val w cap gains; I3: ag assets \& livestk; Y: mthly income; B: net credit

Land $^{\dagger}$ refers to capital gains-adjusted land values, as in Equation 6

SUR with constraint $\mathrm{C}+\mathrm{S}+\mathrm{I} 1+\mathrm{I} 2+\mathrm{I} 3-4 \mathrm{Y}-\mathrm{B}=$ cash grant

All quantities in UGX; Outliers top/bottom coded to 95 th $/ 5$ th percentile

Controls include: base \& mid levels of outcome, income, patience, gender, hh head, age, age ${ }^{2}$, num ad females, num ad males, num children

${ }^{*} p<0.1,{ }^{* *} p<.05,{ }^{* * *} p<0.01$ 


\section{Table 8: Grant effects on components of the household budget constraint - Second endline}

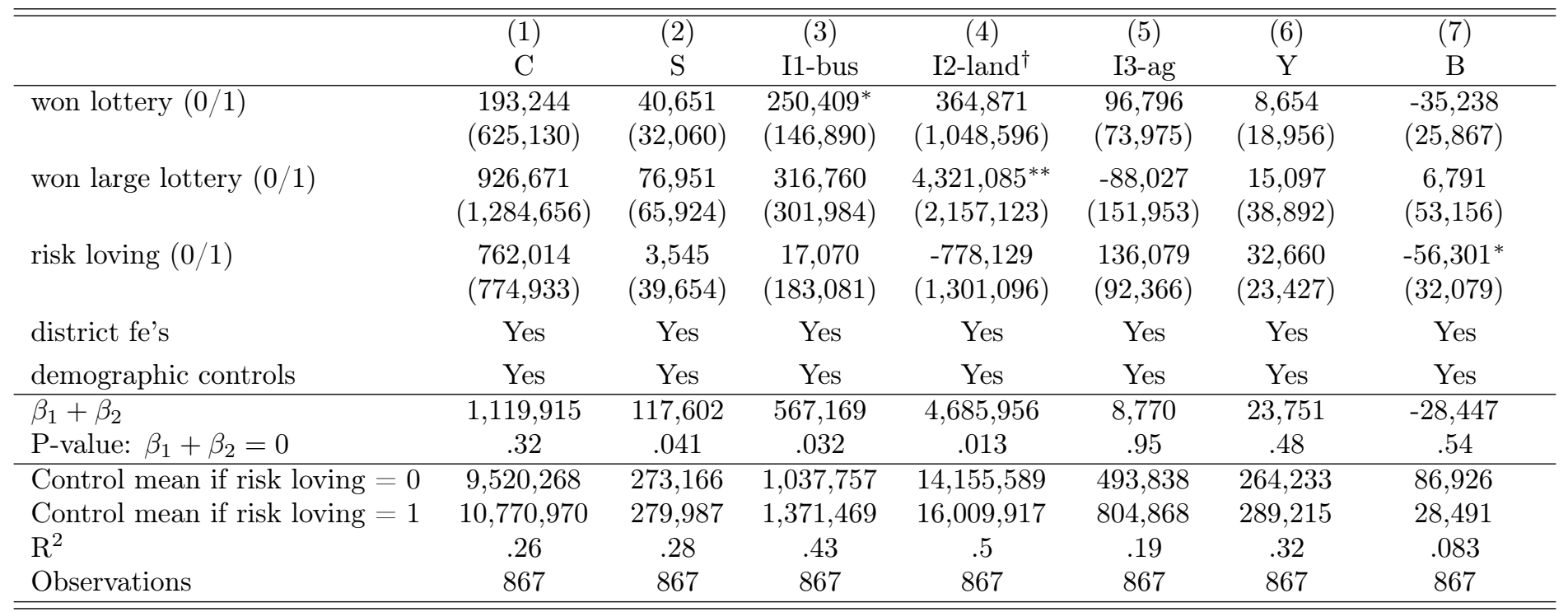

Standard errors in parentheses

C: home dur \& cons; S: savings; I1: bus assets; I2: land val w cap gains; I3: ag assets \& livestk; Y: mthly income; B: net credit

Land $^{\dagger}$ refers to capital gains-adjusted land values, as in Equation 6

All quantities in UGX; Outliers top/bottom coded to 95th/5th percentile

Controls include: pre-treatment levels of outcome, income, patience, gender, hh head, age, age ${ }^{2}$, num ad females, num ad males, num children

${ }^{*} p<0.1,{ }^{* *} p<.05,{ }^{* * *} p<0.01$ 
Table 9: SUR with household budget constraint - Second endline

\begin{tabular}{|c|c|c|c|c|c|c|c|}
\hline & $\mathrm{C}$ & $\mathrm{S}$ & I1-bus & I2-land $^{\dagger}$ & I3-ag & $\mathrm{Y}$ & $\mathrm{B}$ \\
\hline won lottery $(0 / 1)$ & $\begin{array}{c}68,457 \\
(496,023)\end{array}$ & $\begin{array}{c}40,736 \\
(30,836)\end{array}$ & $\begin{array}{l}247,391^{*} \\
(141,124)\end{array}$ & $\begin{array}{c}54,782 \\
(524,245)\end{array}$ & $\begin{array}{c}93,040 \\
(70,646)\end{array}$ & $\begin{array}{c}10,512 \\
(19,310)\end{array}$ & $\begin{array}{l}-34,805 \\
(25,588)\end{array}$ \\
\hline won large lottery $(0 / 1)$ & $\begin{array}{c}-215,170 \\
(1,019,607)\end{array}$ & $\begin{array}{c}51,395 \\
(63,404)\end{array}$ & $\begin{array}{c}209,119 \\
(290,125)\end{array}$ & $\begin{array}{c}1,690,460 \\
(1,077,435)\end{array}$ & $\begin{array}{l}-151,674 \\
(145,124)\end{array}$ & $\begin{array}{c}12,433 \\
(39,627)\end{array}$ & $\begin{array}{c}10,341 \\
(52,581)\end{array}$ \\
\hline risk loving $(0 / 1)$ & $\begin{array}{l}1,124,537 \\
(713,190)\end{array}$ & $\begin{array}{c}11,370 \\
(38,841)\end{array}$ & $\begin{array}{c}63,782 \\
(179,084)\end{array}$ & $\begin{array}{c}147,931 \\
(1,093,005)\end{array}$ & $\begin{array}{l}167,506^{*} \\
(90,210)\end{array}$ & $\begin{array}{c}32,207 \\
(23,875)\end{array}$ & $\begin{array}{c}-57,261^{*} \\
(31,751)\end{array}$ \\
\hline district fe's & Yes & Yes & Yes & Yes & Yes & Yes & Yes \\
\hline demographic controls & Yes & Yes & Yes & Yes & Yes & Yes & Yes \\
\hline $\begin{array}{l}\text { Within-equation tests: } \\
\beta_{1}+\beta_{2} \\
\text { P-value: } \beta_{1}+\beta_{2}=0 \\
\text { Cross-equation tests: }\end{array}$ & $\begin{array}{c}-146,713 \\
.87\end{array}$ & $\begin{array}{c}92,131 \\
.096\end{array}$ & $\begin{array}{c}456,509 \\
.071\end{array}$ & $\begin{array}{c}1,745,241 \\
.063\end{array}$ & $\begin{array}{c}-58,635 \\
.64\end{array}$ & $\begin{array}{c}22,944 \\
.51\end{array}$ & $\begin{array}{c}-24,464 \\
.59\end{array}$ \\
\hline $\begin{array}{l}\text { Small grant } \\
\text { Large grant }\end{array}$ & $\begin{array}{l}\text { P-value: } \\
\text { P-value: }\end{array}$ & $\begin{array}{l}\text { Constraint } \\
\text { Constraint }\end{array}$ & $\begin{array}{l}.72 \\
.13 \\
\end{array}$ & $\begin{array}{l}95 \% \text { CI: } \\
95 \% \text { CI: }\end{array}$ & $\begin{array}{l}\text { ROI } \\
\text { ROI }\end{array}$ & $\begin{array}{l}{[-0.98,1.81]} \\
{[-0.08,0.82]}\end{array}$ & $\begin{array}{l}\text { Mean: } .41 \\
\text { Mean: } .37\end{array}$ \\
\hline Control mean if risk loving $=0$ & $9,520,268$ & 273,166 & $1,037,757$ & $14,155,589$ & 493,838 & 264,233 & 86,926 \\
\hline Control mean if risk loving $=1$ & $10,770,970$ & 279,987 & $1,371,469$ & $16,009,917$ & 804,868 & 289,215 & 28,491 \\
\hline $\mathrm{R}^{2}$ & .26 & .28 & .43 & .5 & .19 & .31 & .083 \\
\hline Observations & 867 & 867 & 867 & 867 & 867 & 867 & 867 \\
\hline
\end{tabular}

Standard errors in parentheses

C: home dur \& cons; S: savings; I1: bus assets; I2: land val w cap gains; I3: ag assets \& livestk; Y: mthly income; B: net credit

Land $^{\dagger}$ refers to capital gains-adjusted land values, as in Equation 6

SUR with constraint $\mathrm{C}+\mathrm{S}+\mathrm{I} 1+\mathrm{I} 2+\mathrm{I} 3-18 \mathrm{Y}-\mathrm{B}=$ cash grant

All quantities in UGX; Outliers top/bottom coded to 95 th/5th percentile

Controls include: base \& mid levels of outcome, income, patience, gender, hh head, age, age ${ }^{2}$, num ad females, num ad males, num children

${ }^{*} p<0.1,{ }^{* *} p<.05,{ }^{* * *} p<0.01$ 
Table 10: Calibration Parameters and Moments

\begin{tabular}{llc}
\hline \hline A. & Assigned Parameters & \\
$r$ & interest rate & 0.00 \\
$\theta$ & borrowing limit & 0.00 \\
$\delta$ & depreciation rate & 0.01 \\
$p$ & survival probability & $1-1 / 480$ \\
& & \\
B. & Calibrated Parameters & \\
$\beta$ & discount factor & 0.84 \\
$\underline{k}$ & size of capital unit & 8.02 \\
$\alpha$ & capital elasticity in production & 0.35 \\
$\mu_{z}$ & mean productivity & 0.96 \\
$\nu_{z}$ & persistent productivity dispersion & 0.35 \\
$\sigma_{z}$ & productivity shock dispersion & 1.13 \\
$\nu_{e}$ & income dispersion & 0.43 \\
$\sigma_{e}$ & income productivity shock dispersion & 0.53 \\
& & \\
\hline
\end{tabular}

\section{Moments}

Income Distributions

P10

P25

P50

P75

P90

Mean

$\underline{\text { Model Data }}$

$\begin{array}{ll}0.39 & 0.15\end{array}$

$0.60 \quad 0.41$

$\begin{array}{ll}1.00 & 1.00\end{array}$

$1.88 \quad 2.04$

$4.18 \quad 3.72$

$1.98 \quad 1.73$

Savings Distributions

P10

P25

P50

P75

P90

Mean

$0.00 \quad-1.85$

$0.00 \quad 0.00$

$0.13 \quad 0.19$

$0.47 \quad 1.16$

$1.43 \quad 2.92$

$0.80 \quad 0.56$

Lottery Choice

Choose Risky Now

Choose Safe Now

Choose Risky Delay

Choose Safe Delay

$\begin{array}{ll}0.20 & 0.20 \\ 0.56 & 0.59 \\ 0.04 & 0.07 \\ 0.19 & 0.14\end{array}$

\section{Income Tercile Transition Probabilities}

\begin{tabular}{lccc} 
& \multicolumn{3}{c}{ Current } \\
Future & \multicolumn{3}{c}{ Model } \\
Low & Low & Medium & High \\
Medium & 0.53 & 0.36 & 0.11 \\
Hih & 0.35 & 0.43 & 0.22 \\
& 0.12 & 0.22 & 0.67 \\
& & & \\
Low & & Data & \\
Medium & Low & Medium & High \\
High & 0.63 & 0.24 & 0.13 \\
\hline \hline
\end{tabular}

\footnotetext{
${ }^{\dagger}$ Future measurements are taken after 16 months
} 
Table 11: Model-Simulated Monte Carlo Regressions

\begin{tabular}{|c|c|c|c|c|}
\hline \multirow[b]{3}{*}{ Simulated Data, Estimation } & \multicolumn{4}{|c|}{ Won Small Lottery } \\
\hline & \multicolumn{4}{|c|}{ SUR Budget Constraint } \\
\hline & $\begin{array}{c}\text { Mean } \\
\text { Investment } \\
\text { Coefficient }\end{array}$ & $\begin{array}{c}\text { Mean } \\
\text { Standard } \\
\text { Error }\end{array}$ & $\begin{array}{c}\text { Mean } \\
\text { p-Value }\end{array}$ & $\begin{array}{c}\text { Rejected } \\
\text { at } 5 \%\end{array}$ \\
\hline True Values, OLS & 3,591 & 5,478 & & . \\
\hline True Values, SUR & 3,578 & 5,651 & 0.56 & 0.04 \\
\hline Empirical Proxy ${ }^{\dagger}$ SUR & 3,617 & 5,639 & 0.50 & 0.05 \\
\hline Measurement Error,$^{\dagger \dagger}$ OLS & 359,806 & 847,510 & & . \\
\hline \multirow[t]{2}{*}{ Measurement Error ${ }^{\dagger \dagger} \mathrm{SUR}$} & $-2,812$ & 99,522 & 0.48 & 0.03 \\
\hline & \multicolumn{4}{|c|}{ Won Large Lottery } \\
\hline True Values, OLS & $2,030,588$ & 11,837 & . & . \\
\hline True Values, SUR & $2,030,840$ & 12,208 & 0.73 & 0.01 \\
\hline Empirical Proxy ${ }^{\dagger}$ SUR & $2,030,997$ & 12,185 & 0.16 & 0.54 \\
\hline Measurement Error,$^{\dagger \dagger}$ OLS & $4,123,745$ & $1,834,133$ & & . \\
\hline Measurement Error ${ }^{\dagger \dagger}$ SUR & $2,103,282$ & 215,348 & 0.28 & 0.38 \\
\hline
\end{tabular}

The natural empirical analogs are the estimates from land investment equation in Tables 6 (OLS) and 7 (SUR). The coefficients coefficients for winning the (small) lottery are $-769,504$ (standard error: 884,518$)$ and $-284,785(206,677)$ for the OLS and SUR estimations, respectively. The coefficients for additionally winning the large lottery are 4,791,936 $(1,819,589)$ and 1,522,877 $(424,702)$ for the OLS and SUR estimations, respectively.

$\dagger$ Empirical Proxy data constructs total consumption between endline and midline by multiplying the value of endline consumption times the number of months minus one and adding consumption from the month directly after the midline as we do to construct consumption in the empirics. OLS estimates are omitted since, for investment, they are identical to True Values, OLS.

$\dagger^{\dagger}$ Measurement Error data multiplies simulated land realizations by the random variable, $X=\tilde{X} \mu_{e}$, where $\tilde{X}$ is a log-normally distributed random variable with mean of one and $\log$ variance of $\nu_{e}^{2}$. Here $\nu_{e}=1.9$ is calibrated to match the average standard error on the coefficient for winning the large lottery to our empirical standard error in Table 6 (i.e., 1,819,589). This matching value is italicized. The coefficient $m u_{e}=2.2$ captures the bias in measurement and its value is calibrated to equal the average ratio of expenditures to income in the pre-experimental data. 
Table 12: Counterfactual Aggregate Impacts of Financial Interventions

\begin{tabular}{|c|c|c|c|c|c|}
\hline & \multirow[t]{2}{*}{$\begin{array}{c}\text { Benchmark } \\
(\theta=0, r=0)\end{array}$} & \multicolumn{2}{|c|}{$\begin{array}{c}\text { Credit } \\
(\theta=0.25)\end{array}$} & \multicolumn{2}{|c|}{$\begin{array}{c}\text { Savings } \\
(r=0.05)\end{array}$} \\
\hline & & $\underline{\mathrm{PE}}$ & $\underline{\mathrm{GE}}$ & $\underline{\mathrm{PE}}$ & $\underline{\mathrm{GE}}$ \\
\hline Agg. Income (=Consumption) & 1.00 & 1.53 & 1.00 & 1.22 & 1.04 \\
\hline Agg. Net Savings & 1.00 & 0.91 & 0.38 & 1.76 & 1.37 \\
\hline Agg. Capital & 1.00 & 2.30 & 1.00 & 1.39 & 1.00 \\
\hline Value of Capital & 1.00 & 2.30 & 1.33 & 1.39 & 1.10 \\
\hline Price of Capital & 1.00 & 1.00 & 1.33 & 1.00 & 1.11 \\
\hline Capital Income & 1.00 & 2.32 & 1.00 & 1.45 & 1.04 \\
\hline Fraction Poor & 1.00 & 0.68 & 1.00 & 0.70 & 0.77 \\
\hline Probability of Staying Poor & 1.00 & 1.00 & 1.00 & 0.77 & 0.76 \\
\hline
\end{tabular}

Notes: Values are reported relative to the benchmark, which has been normalized to one. Initial benchmark values are aggregate income $=$ aggregate consumption $=2.10$, aggregate net savings $=0.86$, aggregate capital $=1.59$, price of capital $=1.00$, capital income $=0.85$, fraction poor $=0.33$, and probability of staying poor $=0.42$. Those people whose wealth is below the initial $33.33 \%$ of the wealth distribution are considered poor, and the probability of staying poor is calculated if they are poor 16 months later, conditional on being poor initially. PE fixes the price of capital to 1 . GE fixes the aggregate quantity of capital to that in the benchmark. In both cases, these values that are constant by construction are indicated by italics. 
Table 13: First stage regressions: Predicting area land value change with lottery outcomes

\begin{tabular}{|c|c|c|c|c|}
\hline & $\begin{array}{c}1) \\
\Delta \text { land val }_{\text {e1-b }} \\
0.5 \mathrm{mi}\end{array}$ & $\begin{array}{c}\text { (2) } \\
\Delta{\text { land } \mathrm{val}_{\mathrm{e} 2-\mathrm{b}}}_{0.5 \mathrm{mi}}\end{array}$ & $\begin{array}{c}(3) \\
\Delta \text { land val }_{\mathrm{e} 1-\mathrm{b}} \\
1 \mathrm{mi}\end{array}$ & $\begin{array}{c}(4) \\
\Delta \text { land val }_{\text {e2-b }} \\
1 \mathrm{mi}\end{array}$ \\
\hline winnings within $0.5 \mathrm{mi}$ & $\begin{array}{l}5.4^{* *} \\
(2.1)\end{array}$ & $\begin{array}{c}3.9 \\
(3.1)\end{array}$ & & \\
\hline winnings within $1 \mathrm{mi}$ & & & $\begin{array}{l}11^{* * *} \\
(2.5)\end{array}$ & $\begin{array}{l}13^{* * *} \\
(3.7)\end{array}$ \\
\hline num risk lovers within $0.5 \mathrm{mi}$ & $\begin{array}{l}-2,342,748 \\
(2,058,193)\end{array}$ & $\begin{array}{c}-5,545,858^{*} \\
(3,220,854)\end{array}$ & & \\
\hline num houses within $0.5 \mathrm{mi}$ & $\begin{array}{c}2,988,866^{* * *} \\
(906,067)\end{array}$ & $\begin{array}{c}7,997,012^{* * *} \\
(1,231,773)\end{array}$ & & \\
\hline num risk lovers within $1 \mathrm{mi}$ & & & $\begin{array}{c}-1,760,532 \\
(2,517,342)\end{array}$ & $\begin{array}{l}-3,419,500 \\
(3,635,333)\end{array}$ \\
\hline num houses within $1 \mathrm{mi}$ & & & $\begin{array}{c}2,198,791^{* *} \\
(861,463)\end{array}$ & $\begin{array}{c}6,615,931^{* * *} \\
(1,338,197)\end{array}$ \\
\hline lottery winnings & $\begin{array}{c}.5 \\
(1.9)\end{array}$ & $\begin{array}{c}-2.1 \\
(3)\end{array}$ & $\begin{array}{c}2.5 \\
(3.9)\end{array}$ & $\begin{array}{c}-.71 \\
(6.1)\end{array}$ \\
\hline risk loving $(0 / 1)$ & $\begin{array}{l}-2,961,244 \\
(2,833,148)\end{array}$ & $\begin{array}{c}-5,201,103 \\
(4,533,648)\end{array}$ & $\begin{array}{l}-4,265,630 \\
(4,180,763)\end{array}$ & $\begin{array}{l}-4,675,803 \\
(6,206,888)\end{array}$ \\
\hline $\operatorname{land}_{\mathrm{b}}$ & $\begin{array}{c}.14 \\
(.096)\end{array}$ & $\begin{array}{l}.081 \\
(.17)\end{array}$ & $\begin{array}{l}.24 \\
(.15)\end{array}$ & $\begin{array}{l}.29 \\
(.25)\end{array}$ \\
\hline mthly income $_{\mathrm{m}}$ & $\begin{array}{l}-4.3 \\
(3.4)\end{array}$ & $\begin{array}{c}-8.6 \\
(6)\end{array}$ & $\begin{array}{l}-5.9 \\
(5.8)\end{array}$ & $\begin{array}{l}-10 \\
(9.8)\end{array}$ \\
\hline district fe's & Yes & Yes & Yes & Yes \\
\hline demographic controls & Yes & Yes & Yes & Yes \\
\hline Control mean & $32,156,806$ & $67,553,376$ & $60,968,333$ & $125,413,334$ \\
\hline $\mathrm{R}^{2}$ & .29 & .4 & .39 & .51 \\
\hline Observations & 867 & 867 & 867 & 867 \\
\hline
\end{tabular}

All quantities in UGX; Outliers top/bottom coded to 95 th/5th percentile

Controls include: patience, gender, hh head, age, age $^{2}$, num ad females, num ad males, num children

Standard errors clustered within geographic neighborhoods

${ }^{*} p<0.1,{ }^{* *} p<.05,{ }^{* * *} p<0.01$ 
Table 14: Instrumenting change in area land value with lottery results

\begin{tabular}{|c|c|c|c|c|}
\hline & $\begin{array}{c}(1) \\
\operatorname{land}_{\mathrm{e} 1}\end{array}$ & $\begin{array}{c}(2) \\
\operatorname{land}_{\mathrm{e} 2}\end{array}$ & $\begin{array}{c}(3) \\
\text { land }_{\mathrm{e} 1}\end{array}$ & $\begin{array}{c}(4) \\
\text { land }_{\mathrm{e} 2}\end{array}$ \\
\hline$\Delta$ land val ${ }_{\text {e1-b }} 0.5 \mathrm{mi}$ & $\begin{array}{l}.066 \\
(.044)\end{array}$ & & & \\
\hline$\Delta$ land val ${ }_{\text {e2-b }} 0.5 \mathrm{mi}$ & & $\begin{array}{r}-.048 \\
(.14)\end{array}$ & & \\
\hline$\Delta$ land val $_{\mathrm{e} 1-\mathrm{b}} 1 \mathrm{mi}$ & & & $\begin{array}{l}.042^{* *} \\
(.017)\end{array}$ & \\
\hline$\Delta$ land val $_{\text {e2-b }} 1 \mathrm{mi}$ & & & & $\begin{array}{c}.034 \\
(.023)\end{array}$ \\
\hline num risk lovers within $0.5 \mathrm{mi}$ & $\begin{array}{c}2,873 \\
(285,705)\end{array}$ & $\begin{array}{c}-627,942 \\
(779,336)\end{array}$ & & \\
\hline num houses within $0.5 \mathrm{mi}$ & $\begin{array}{c}-376,048^{*} \\
(209,512)\end{array}$ & $\begin{array}{c}334,098 \\
(1,214,962)\end{array}$ & & \\
\hline num risk lovers within $1 \mathrm{mi}$ & & & $\begin{array}{c}-207,493 \\
(208,600)\end{array}$ & $\begin{array}{l}-372,638 \\
(316,951)\end{array}$ \\
\hline num houses within $1 \mathrm{mi}$ & & & $\begin{array}{c}-148,115^{*} \\
(88,175)\end{array}$ & $\begin{array}{l}-257,552 \\
(235,264)\end{array}$ \\
\hline lottery winnings & $\begin{array}{l}1.9^{* *} \\
(.96)\end{array}$ & $\begin{array}{l}3.7^{* *} \\
(1.7)\end{array}$ & $\begin{array}{l}1.7^{*} \\
(.9)\end{array}$ & $\begin{array}{l}3.7^{* *} \\
(1.6)\end{array}$ \\
\hline risk loving $(0 / 1)$ & $\begin{array}{c}-697,218 \\
(881,242)\end{array}$ & $\begin{array}{c}-884,216 \\
(1,425,026)\end{array}$ & $\begin{array}{c}-612,780 \\
(844,177)\end{array}$ & $\begin{array}{c}-407,990 \\
(1,377,382)\end{array}$ \\
\hline $\operatorname{land}_{\mathrm{b}}$ & $\begin{array}{l}1.2^{* * *} \\
(.047)\end{array}$ & $\begin{array}{l}1.1^{* * *} \\
(.071)\end{array}$ & $\begin{array}{l}1.2^{* * *} \\
(.046)\end{array}$ & $\begin{array}{c}1.1^{* * *} \\
(.07)\end{array}$ \\
\hline mthly income $_{m}$ & $\begin{array}{c}3.1^{* * *} \\
(1.2)\end{array}$ & $\begin{array}{c}9.8^{* * *} \\
(2.5)\end{array}$ & $\begin{array}{c}3^{* *} \\
(1.2)\end{array}$ & $\begin{array}{c}10^{* * *} \\
(2.2)\end{array}$ \\
\hline district fe's & Yes & Yes & Yes & Yes \\
\hline demographic controls & Yes & Yes & Yes & Yes \\
\hline First stage F-stat & 6.7 & 1.6 & 20 & 13 \\
\hline Control mean & $16,266,186$ & $21,144,573$ & $16,266,186$ & $21,144,573$ \\
\hline Observations & 867 & 867 & 867 & 867 \\
\hline
\end{tabular}

All quantities in UGX; Outliers top/bottom coded to 95 th/5th percentile

Conrols include: patience, gender, hh head, age, age $^{2}$, num ad females, num ad males, num children Instrumenting area land value change since baseline with other households' lottery winnings Standard errors clustered within geographic neighborhoods

${ }^{*} p<0.1,{ }^{* *} p<.05,{ }^{* * *} p<0.01$ 